\title{
Measuring $\mathrm{SO}_{2}$ ship emissions with an ultraviolet imaging camera
}

\author{
A. J. Prata \\ Nicarnica Aviation AS 2007, Kjeller, Norway \\ Correspondence to: A. J. Prata (fp@ nicarnicaaviation.com) \\ Received: 6 September 2013 - Published in Atmos. Meas. Tech. Discuss.: 5 November 2013 \\ Revised: 3 March 2014 - Accepted: 7 March 2014 - Published: 12 May 2014
}

\begin{abstract}
Over the last few years fast-sampling ultraviolet (UV) imaging cameras have been developed for use in measuring $\mathrm{SO}_{2}$ emissions from industrial sources (e.g. power plants; typical emission rates $\sim 1-10 \mathrm{~kg} \mathrm{~s}^{-1}$ ) and natural sources (e.g. volcanoes; typical emission rates $\sim 10$ $100 \mathrm{~kg} \mathrm{~s}^{-1}$ ). Generally, measurements have been made from sources rich in $\mathrm{SO}_{2}$ with high concentrations and emission rates. In this work, for the first time, a UV camera has been used to measure the much lower concentrations and emission rates of $\mathrm{SO}_{2}$ (typical emission rates $\sim 0.01-0.1 \mathrm{~kg} \mathrm{~s}^{-1}$ ) in the plumes from moving and stationary ships. Some innovations and trade-offs have been made so that estimates of the emission rates and path concentrations can be retrieved in real time. Field experiments were conducted at Kongsfjord in $\mathrm{Ny}$ Ålesund, Svalbard, where $\mathrm{SO}_{2}$ emissions from cruise ships were made, and at the port of Rotterdam, Netherlands, measuring emissions from more than 10 different container and cargo ships. In all cases $\mathrm{SO}_{2}$ path concentrations could be estimated and emission rates determined by measuring ship plume speeds simultaneously using the camera, or by using surface wind speed data from an independent source. Accuracies were compromised in some cases because of the presence of particulates in some ship emissions and the restriction of single-filter UV imagery, a requirement for fastsampling $(>10 \mathrm{~Hz})$ from a single camera. Despite the ease of use and ability to determine $\mathrm{SO}_{2}$ emission rates from the UV camera system, the limitation in accuracy and precision suggest that the system may only be used under rather ideal circumstances and that currently the technology needs further development to serve as a method to monitor ship emissions for regulatory purposes. A dual-camera system or a single, dual-filter camera is required in order to properly correct for the effects of particulates in ship plumes.
\end{abstract}

\section{Introduction}

There is strong interest in measuring volcanic gases (e.g. $\mathrm{SO}_{2}, \mathrm{HCl}, \mathrm{CO}_{2}$ ) in order to provide insights into important processes, for example, for monitoring of volcanic gas flux rate changes in reawakening volcanoes in order to forecast future behaviour. Measurements of volcanic $\mathrm{SO}_{2}$ also help to constrain the budget of the atmospheric sulfur cycle (e.g. Berresheim and Jaeschke, 1983, and Graf et al., 1997). In these examples, high precision and accuracy are less important; rather, the priority is that of quantification of the gas concentration and ideally rapid and safe identification. Polluting gases from industrial sources also need to be monitored, especially in the developing world where industrial emission standards may be low and problematic to enforce. Gases also leak from industrial plants and pipelines, and toxic gas releases from industrial accidents or from deliberate acts require identification and monitoring at a safe distance. McElhoe and Conner (1986) used a portable UVsensitive video camera system to successfully measure the $\mathrm{SO}_{2}$ emissions from 12 industrial stacks. These applications have driven the development of new imaging cameras that operate in narrow band intervals within the ultraviolet $(280-320 \mathrm{~nm})$ part of the electromagnetic spectrum. Most of these developments have occurred in volcanological research, for example, Bluth et al. (2007), Mori and Burton (2006), Oppenheimer et al. (1998), Kern et al. (2010), but there is potentially a much wider application.

Measurements of emissions of polluting gases from ships at sea or at anchor with engines running are of interest because of the harmful effects these emissions have on the local environment. $\mathrm{SO}_{2}$ is a toxic gas responsible for many deleterious effects on the environment, including acid rain, smog, and damage to vegetation, and in some cases, to human health. $\mathrm{SO}_{2}$ degrades air quality and can alter the radiation 
balance through the formation of aerosols that intercept and scatter light. The European Union (EU) has regulated that sulfur (S) in fuel (causing $\mathrm{SO}_{2}$ ship emissions) should be controlled within closed waterways, harbours and in proximity to environmentally vulnerable areas. The International Maritime Organisation (IMO) caps the global sulfur content of marine fuel at $3.5 \%$ starting in January 2012 - Annex VI to the International Convention for the Prevention of Pollution from Ships (MARPOL Annex VI). Preference is for S content to be below $0.5 \%$ for ships in harbours and at $0.1 \%$ for ships at berth.

The European Union has sought advice from the scientific community on the techniques and methods for determining $\mathrm{SO}_{2}$ emissions within harbours in order to assist with regulatory controls regarding the allowed $\mathrm{S}$ content in maritime fuel. The Joint Research Centre (JRC) devised a research activity to investigate potential technologies for this problem. Balzani Lööv et al. (2013) describe the overall research program and the measurement campaigns planned to compare the candidate technologies. This paper focuses on the results of one of the measurement campaigns: the SIRENAS-R campaign and complements other papers in this Special Issue. Since the paper introduces, for the first time, the use of a novel UV camera imaging system to quantify ship emissions, some background to the development of the system, example prior measurements, and how the measurement protocol has been developed are necessary. The paper is therefore mostly concerned with introducing a new atmospheric measurement technique and follows these logical steps: the background to the ship experiments and some results from a preliminary campaign are presented first. A brief description of the campaigns is provided followed by a methods section that includes a description of the camera system, calibration of the camera, details of the retrieval method and some specifics on how the relevant parameters are estimated. The main results of the SIRENAS-R campaign are provided, but since the comparison to the other measurements made during the campaign are presented in the paper by Balzani Lööv et al. (2013), there is no section on validation in this paper. A brief set of conclusions is given with an emphasis on the novelty of the measurement technique and the current limitations.

\section{Background to the ship experiments}

As with any new measurement technique, it is necessary to start with a theoretical analysis, build an experimental system and then improve the technique based on experience and experimental results. Theoretical studies can be found in the papers cited in the Introduction, particularly the paper by Kern et al. (2010). An experimental UV camera system has been described by Bluth et al. (2007), among others. For ship plume measurements, two innovations were needed: a faster sampling UV camera and a high quantum efficiency CCD.

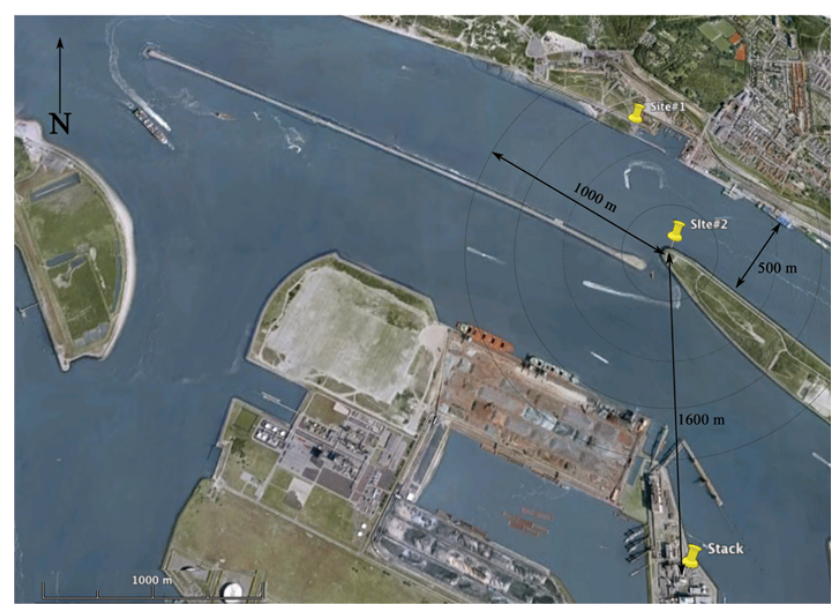

Fig. 1. Map of the shipping lanes at Hoek van Holland. The measurement sites are marked (site no. 1 and site no. 2) and the location of a nearby stack, used to verify the distance measurements is also indicated. Ships moving along the shipping lane (inbound and outbound - to the WNW) were measured at distances varying from 100 to $2000 \mathrm{~m}$. The scale shown is approximate.

Details on the camera system can be found in the Methods section, and we begin with a description of the first measurement campaign.

\subsection{SUVEX measurement campaign}

A scientific research station has been established over the years at Ny Ålesund, Svalbard, at the entrance to a fjord, Kongsfjord $\left(78^{\circ} 55^{\prime} \mathrm{N}, 11^{\circ} 56^{\prime} \mathrm{E}\right)$, fed by a glacier. Activities at the research station include environmental, marine, tropospheric and upper atmospheric experimental research, among others. During the summer season (May-August), sight-seeing cruise ships of various capacities (up to $\sim 3400$ passengers in one case) visit the fjord in greater numbers, and either dock or lie at anchor, often with engines running. Emissions from these ships disturb the otherwise pristine atmosphere and can affect the quality of baseline atmospheric measurements made routinely at an elevated site in Ny Ålesund. For two weeks in late July and early August 2009, a fast-sampling UV camera was set-up and used to estimate the $\mathrm{SO}_{2}$ emissions from visiting cruise ships. The measurement campaign - Svalbard UltraViolet camera experiment (SUVEX) - permitted the first test of the camera system and served to investigate whether the system could detect and quantify relatively low $\mathrm{SO}_{2}$ ship emission rates of $\sim 2-20 \mathrm{~g} \mathrm{~s}^{-1}$. During the campaign, a measurement protocol was established, measurements of emissions from seven ships were made (sometimes multiple times), quantitative retrievals of the $\mathrm{SO}_{2}$ path amount calculated and the limitations of the system recognised. These are reported in the Results section. 
Table 1. Specifications of the Hamamatsu charge-coupled detector (CCD) chip and optics.

\begin{tabular}{ll}
\hline Wavelength range & $200-600 \mathrm{~nm}$ \\
Pixels & $1344 \times 1024$ \\
Horizontal pixel size & $4.65 \mu \mathrm{m}$ \\
Vertical pixel size & $4.65 \mu \mathrm{m}$ \\
Horizontal chip size & $6.25 \mathrm{~mm}$ \\
Vertical chip size & $4.76 \mathrm{~mm}$ \\
UV lens & $50 \mathrm{~mm} \mathrm{f} / 3.5$ \\
UV filter & $308 \pm 5 \mathrm{~nm}$ \\
Quantum efficiency & $\sim 30 \%$ at $300 \mathrm{~nm}$ \\
Digitisation & $12 \mathrm{bits}$ \\
\hline
\end{tabular}

\subsection{SIRENAS-R measurement campaign}

The SIRENAS-R campaign was conducted under the auspices of the European Joint Research Centre (JRC) during September 2009 to investigate the utility of certain technologies for estimating the $\mathrm{S}$ content in marine fuel. The motivation for this is to provide the relevant authorities with tools that can quickly assess the fuel S content, determined from emission measurements, for compliance with new European Union directives. Currently the permitted S content in fuel used for shipping is $0.5 \%$ by mass with a new limit to be imposed for ships operating within harbours of $0.1 \%$ by mass. Emission measurements by themselves are not sufficient to determine the mass fraction of $\mathrm{S}$ in fuel as they depend on engine efficiency factors as well as the power loading of the engines (see Corbett and Fischbeck, 1997, and Corbett and Koehler, 2003). During the campaign, chemical "sniffers" and three different optical methods were tested; these are described by Balzani Lööv et al. (2013) where detailed descriptions of the methods and an inter comparison of results are presented. Here we describe the UV camera system which was used during the campaign and we provide more detailed results of the measurements of ship plume $\mathrm{SO}_{2}$ path amount (ppm $\mathrm{m}$ or $\mathrm{g} \mathrm{m}^{-2}$ ) and emission rate from ships under steam and at dock. A map of the measurement area is shown in Fig. 1

\section{Methods}

\subsection{UV camera}

The UV camera used for these experiments is a highly sensitive CCD array $(1344 \times 1024$ pixels $)$ manufactured by Hamamatsu Photonics, Japan. The quantum efficiency (QE) of the CCD is high from $280-320 \mathrm{~nm}$, which is the main region of interest for measuring $\mathrm{SO}_{2}$ and some other minor atmospheric polluting gases. The transmission of the lens used and a narrow-band filter are also chosen to have high transmission within the spectral region. Table 1 provides the specifications of the chip and optics (see Fig. 2 for the

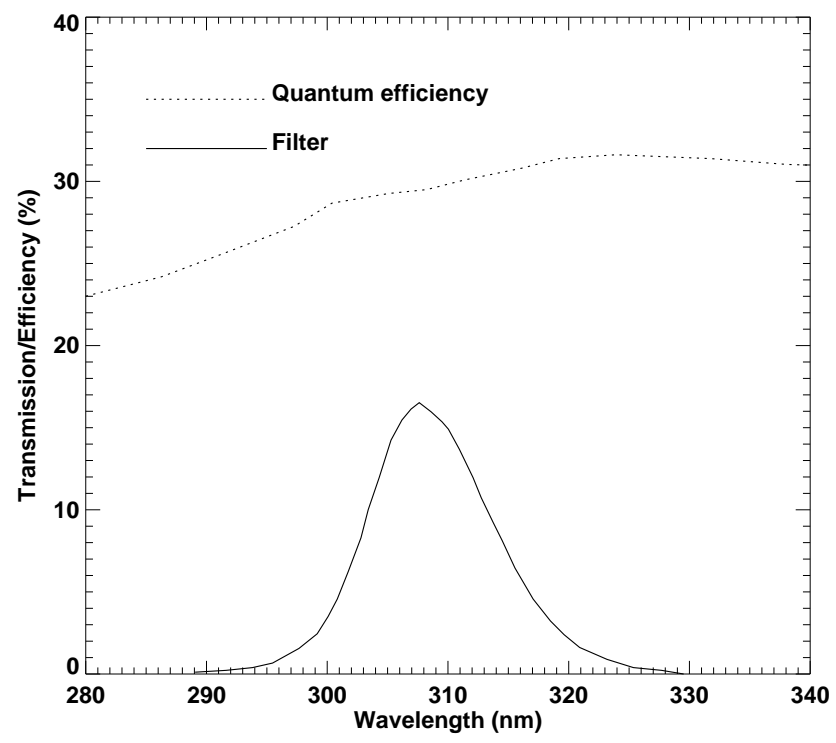

Fig. 2. The Melles Grioot 310PB10 UV narrowband filter transmission and the Hamamatsu CCD quantum efficiency as a function of wavelength.

wavelength variation of the filter transmission and QE of the CCD). The main attribute of this camera is that it can sample very quickly (better than $100 \mathrm{~Hz}$ ) while still maintaining good signal-to-noise ratio (SNR). Fast sampling is necessary because the target is often moving (ships under steam) and the signal is quite low, so that long integration times will smear the images. $\mathrm{SO}_{2}$ emissions from ships are considerably lower than typical volcanic $\mathrm{SO}_{2}$ emissions (by a factor of $10^{4}$ ) and lower than industrial stack $\mathrm{SO}_{2}$ emissions (by a factor of $10^{3}$ ). The camera is controlled using a laptop with a frame grabber and powered by $12 \mathrm{~V}$ batteries or mains power, whichever is more convenient. The system is highly portable, easy to set-up and can be ready for operation within $15 \mathrm{~min}$. A photograph of the camera in operation at Hoek van Holland is provided in Fig. 3. The principle of the measurement has been explained in many papers, e.g. Mori et al. (2006), Platt and Stutz (2008), Tamburello et al. (2011b), Kantzas et al. (2010), Tamburello et al. (2011a), Dalton et al. (2009), Kern (2009) and here just a brief description is given.

\subsection{Data analysis}

$\mathrm{SO}_{2}$ exhibits significant absorption features within the region between $240-338 \mathrm{~nm}$, due to a series of vibrational bands attributed to the transition $\tilde{B}^{1} B_{1}-\tilde{X}^{1} A_{1}$ (Kullmer and Demtrōder, 1985). The absorption system manifests itself as a series of peaks and troughs at fairly uniform wavelength spacing with decreasing magnitude as wavelength increases. Over the years high-resolution spectral absorption measurements have been made for this $\mathrm{SO}_{2}$ transition, mostly at S.T.P conditions, e.g. Vandaele et al. (1994), Bogumil et al. (2003) and Rufus et al. (2003). 


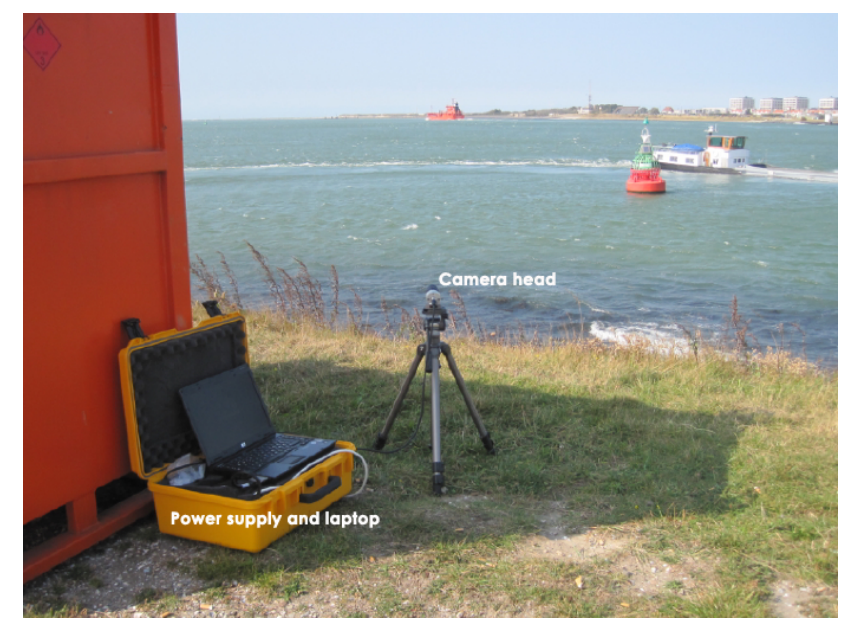

Fig. 3. Photograph of the UV camera mounted on a tripod with laptop and camera box.

The UV camera measures the UV light within a narrow wavelength band. The focal length of the lens is $50 \mathrm{~mm}$ and the total field of view is $7.15^{\circ}$ by $5.45^{\circ}$; at a distance of $1 \mathrm{~km}$ (line of sight, camera to target) each pixel is approximately square with a side length of $\sim 0.2 \mathrm{~m}$. Under good lighting conditions, clear sky and small solar zenith angle, a range of $5 \mathrm{~km}$ provides acceptable signal to noise. At greater distances, the contrast between the light transmitted through the plume and the light from the background is reduced. This light dilution effect is caused by light scattered from the sky (air molecules) into the camera and this affects the signal to noise for the retrieval.

The data reduction utilises a simple strategy: since there is only a single filter, traditional DOAS: differential optical absorption spectroscopy (see Platt and Stutz, 2008, for details) cannot be used and reliance must be made on good calibration and the geometrical properties of the measurement. Light diminution and enhancement along the path, caused by multiple scattering off clouds, water and other objects and scattering and absorption within the band due to other gases (e.g. $\mathrm{O}_{3}, \mathrm{NO}_{2}, \mathrm{BrO}$ ) and particles must either be ignored (assumed negligible) or modelled in some way. The radiative transfer in realistic situations can be quite complex (see Kern et al., 2010, and Kern, 2009, for an excellent treatment of the problem) and so every effort was made to capture data under optimum conditions, namely, good light, short line of sight, low cloudiness, and minimal interference from other gases and particulates. As we shall see it was not always possible to achieve these conditions and some results are certainly degraded because of these effects.

With the assumptions of optimum measurement conditions, the monochromatic radiative transfer problem to be solved may be stated:

$I(\lambda)=I_{0}(\lambda) \exp \{-\tau(\lambda, l)\}$, where $I$ is the measured light intensity at wavelength $\lambda, I_{0}$ is initial intensity before traversing the $\mathrm{SO}_{2}$ plume and $\tau$ is the optical depth,

$\tau(\lambda, L)=\int_{0}^{L} \sigma(\lambda) c(l) \mathrm{d} l$,

$L$ is the total path traversed by the light. This expression is often referred to as the Beer-Bouguer-Lambert law and is strictly valid here for cases with little or no scattering because the extinction coefficient is determined for absorption only. The concentration $c$ along the path $l$ is considered to be constant, reducing Eq. (1) to,

$\rho=c L=\frac{1}{\sigma_{\lambda}} \ln \left[\frac{I_{0}}{I}\right]$,

where $\rho$ is the column mass $\left(\mathrm{g} \mathrm{m}^{-2}\right)$ or path concentration, and $\sigma_{\lambda}$ is the photo-absorption cross section, which is calculated using the laboratory data of Vandaele et al. (1994). With this simplified expression, the retrieval of the $\mathrm{SO}_{2}$ column consists of making two measurements: one of the light intensity before the light has entered the plume and one of the light intensity after traversing the plume. The absorption coefficient is assumed to be known. In practice the measured radiation is not monochromatic and a further assumption is made that the variations across the narrow band (e.g. due to the absorption coefficient) are small. Kern et al. (2010) has explored various assumptions in the radiative transfer and provides the size of the errors and potential problems when using simplified radiative transfer.

One source of uncertainty lies in the estimation of the background light intensity, $I_{0}$. There are several approaches to obtaining $I_{0}$, including:

- Making measurements away from the plume (e.g. $180^{\circ}$ to the plume direction) and assume a uniform background source.

- Calculating $I_{0}$ using a model for the atmosphere based on ancillary atmospheric data.

- Estimating the background using image measurements and a fitting procedure.

The easiest to implement of these three options is the third and this strategy is described in Sect. 3.4.

\subsection{Calibration}

Calibration of the camera was conducted in the laboratory using specially designed quartz glass cells with varying thicknesses and a diameter of $50 \mathrm{~mm}$ matching the camera lens diameter, each filled with different concentrations of $\mathrm{SO}_{2}$ gas. Sunlight from a clear sky illuminates the cell and enters the camera through the filter and lens in exactly the same manner 


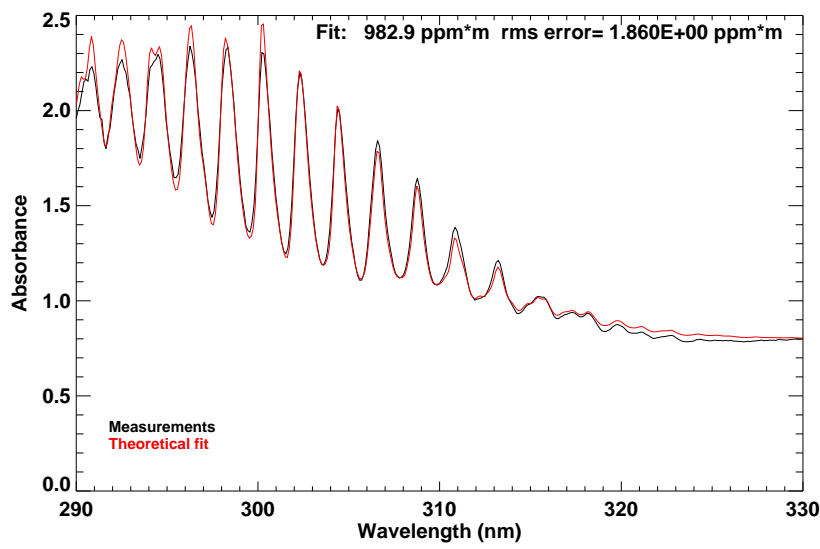

Fig. 4. Spectrometer measurements of the absorbance of UV light through a quartz cell containing $\mathrm{SO}_{2}$ gas. The red line shows the theoretical variation of the absorbance with wavelength, based on the absorption coefficient data of Vandaele et al. (1994).

as expected in the field. The light intensity behind the cell is estimated using Eq. (3). The cells were filled with differing amounts of $\mathrm{SO}_{2}$ giving cell path amounts from $\sim 100 \mathrm{ppm} \mathrm{m}$ to $\sim 2000 \mathrm{ppm} \mathrm{m}$. The path concentrations were checked using an Ocean Optics spectrometer with a fibre optic cable, a blocking filter (Schott glass) and utilising a standard UV lamp as a source. An example is shown in Fig. 4. As the $\mathrm{SO}_{2}$ path concentrations from the ship emissions were expected to be low, the camera was set on a high gain setting which provides better sensitivity to low path amounts but also gives noisier imagery. This can be compensated for by using longer exposure times but ultimately there is a trade-off between sensitivity, noise, and exposure times that are not too long that the ship undergoes noticeable motion. The absorption due to the quartz glass was estimated using an empty cell. For all measurements, a dark signal is removed by capturing images using a blackened plate placed at the entrance to the lens. The calibration curve is quite linear over the range of path amounts, giving a (linear) least squares fit of

$\mathrm{SO}_{2}=A \ln \left[\frac{\mathrm{DN}_{0}}{\mathrm{DN}}\right]+B$,

where $\mathrm{SO}_{2}$ is the path amount measured in ppmm, $\mathrm{DN}_{0}$ are the image digital numbers estimated for the empty cell, and $\mathrm{DN}$ are the measured digital numbers for light passing through the cell with $\mathrm{SO}_{2}$ gas, $A$ and $B$ are the estimated slope and intercept of the linear fit. The resulting fit is shown in Fig. 5. Repeat measurements using the cells with differing solar zenith angles on different days, with variable clear sky atmospheric conditions gave a variability in estimating the logarithm of the ratio of digital numbers Eq. (4) of \pm 0.004 . The spectrometer measurements provide errors of $\sim 3 \%$.

This calibration method permits rapid assessment of the path amounts in ship plumes by simply taking the natural logarithm of the digital numbers. The accuracy is limited

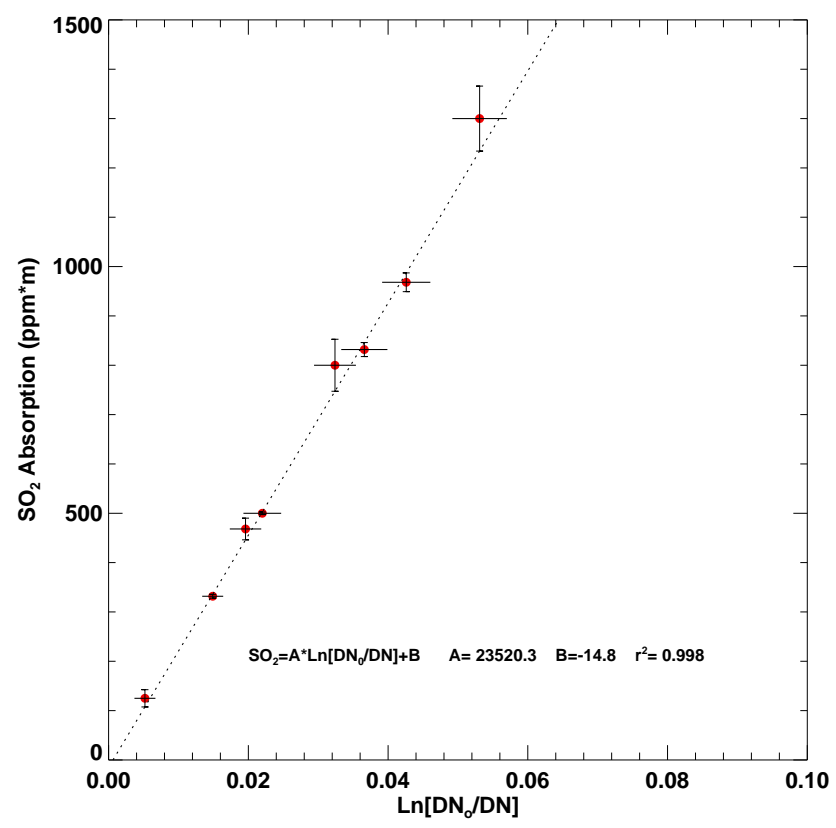

Fig. 5. Calibration curve determined used bright diffuse skylight as a source and $\mathrm{SO}_{2}$ path amounts (in ppm m) in quartz glass cells. The $\mathrm{SO}_{2}$ cell path amounts were independently measured using a spectrometer.

principally by the SNR of the measurement and atmospheric conditions. Because the camera offers quite fast sampling, multiple images can be averaged to improve SNR. Digital count differences $\left(\mathrm{DN}_{0}-\mathrm{DN}\right)$ as low as 5 counts were measured equivalent to $\sim 10 \mathrm{ppm}$ m. For a ship plume of $\sim 10 \mathrm{~m}$ depth, the equivalent $\mathrm{SO}_{2}$ concentration is $\sim 1 \mathrm{ppm}$ or $\sim 2.6 \mathrm{mg} \mathrm{m}^{-3}$ at S.T.P. This is considered to be the lower limit of the measurement capability of the current camera system, under good atmospheric and plume conditions (i.e. bright clear skies and no plume particulates).

Calibration was also performed in the field from time to time using the same cells by inserting them into the camera's field of view while viewing a clear sky. Because the basic principle of the measurement requires a ratio of intensities, changes in gain of the instrument (electronic or optical) are effectively eliminated. The field calibration reduces baseline offsets.

The wavelength response of the camera optics and filter was measured using the Ocean Optics spectrometer and the UV lamp in the laboratory. Changes in the filter response function with angle of incidence of UV light and degradation of the filter with time were not tested, other than through repeat calibrations before and after the field campaign. Since the field of view is quite narrow, unwanted effects due to offaxis light rays are small. No degradation was noticed after 3 months. Alignment of the camera optics was unnecessary as the camera uses a single filter. 


\subsection{Background intensity, $I_{0}$}

The strategy for estimating the background intensity makes the assumption that the light intensity either side of the plume is the same or very similar to that directly behind the plume and is assumed to be the main contribution to the light entering the plume which is subsequently diminished by absorption due to $\mathrm{SO}_{2}$ molecules along the path. Since the field of view angle is quite narrow $\left(<8^{\circ}\right)$ the part of the sky imaged is quite small and so the assumption is reasonable. The optical components that are part of the camera system impart variations across the CCD, even when illuminated by a uniform source. The variation is often referred to as vignetting and is a function of the $F / \#$; it can be reduced by reducing the aperture (increasing the $F / \#$ ), which is only feasible for bright light conditions with a fast-sampling camera of high quantum efficiency. The exact configuration of the optics in the system (e.g. filter behind the lens or in front, field-ofview size, $F / \#$, etc.) determines the size of these unwanted effects and is discussed in Kern et al. (2013) and Lübcke et al. (2013). To illustrate the principle of the method for estimating the background intensity, Fig. 6 shows the image obtained when viewing a calibration cell filled with $\mathrm{SO}_{2}$ gas only and held up against a bright, clear blue sky. A single transect through the image cutting through the centre of the cell is plotted showing the change in light intensity across the image and across the cell. The drop across the cell is due to $\mathrm{SO}_{2}$ absorption, while the drop at the edges of the image is due to the vignetting effect. It has been found that the vignetting effect can be modelled very well using a linear combination of a Gaussian and a cubic equation of the form:

$\mathrm{DN}(p)=A_{0} \exp \left(-\frac{x^{2}}{2}\right)+A_{3}+A_{4} p+A_{5} p^{2}+A_{6} p^{3}$,

$x(p)=\frac{p-A_{1}}{A_{2}}$,

where $p$ is pixel number (measured across the image) and $D N$ is digital number. By using this fitting procedure an estimate of the light intensity behind the attenuated part of the plume can be made. In cases where the ship plume is oriented more in the horizontal than in the vertical, it is necessary to use a vertical transect through the plume. The background intensity is then estimated from a nearby vertical transect that does not intersect the plume. This does, of course, require that some parts of the image are not covered by the plume and that preferably there are clear regions to either side of the plume. It will be seen that for measuring ship plumes this is not a particularly difficult geometry to achieve.

\subsection{Emission estimates}

Emission estimates require an estimate of the plume speed. One method to do this is to use feature tracking within the plume. UV images of a plume from a power plant stack on

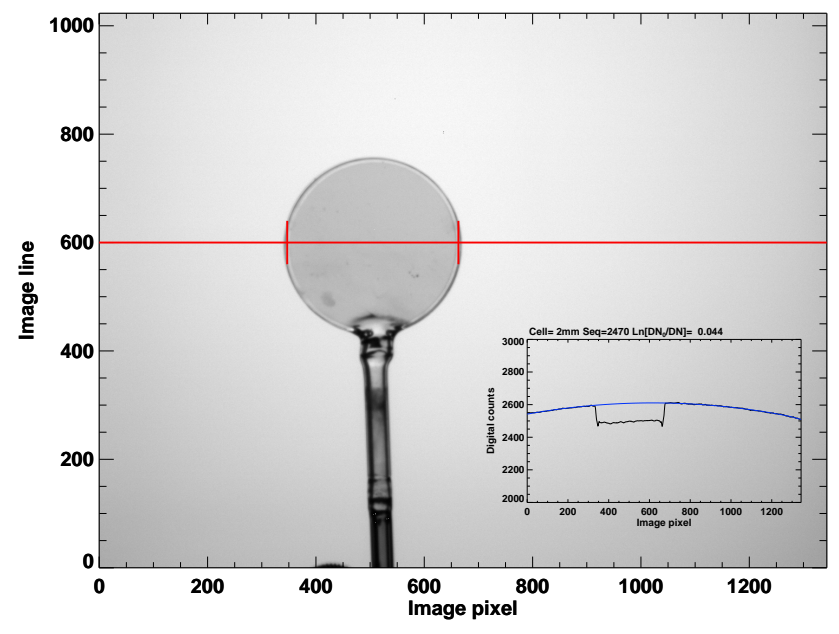

Fig. 6. Camera calibration using a bespoke $\mathrm{SO}_{2}$ cell. The inset plot shows the intensity variation along the red line that cuts through a central part of the cell. The image counts (digital counts or digital numbers) is reduced as the light is attenuated by the $\mathrm{SO}_{2}$ in the cell. The blue line is the Gaussian-cubic fit to the counts. The rapid variations near at the start and end of the intensity drop are due to the edges of the quartz cell and are removed before processing. The amount of $\mathrm{SO}_{2}$ gas in this cell is $\sim 983 \mathrm{ppm} \mathrm{m}$.

the southern side of the shipping channel (see Fig. 1) were used to test the procedure at quite high sampling rates, up to $10 \mathrm{~Hz}$ or so. By tracking small features within the plume an estimate of the plume velocity, $v_{\mathrm{p}}$ can be made. If the path concentration is $u\left(\mathrm{~g} \mathrm{~m}^{-2}\right)$, then by taking a transect (in this case parallel to the $y$ axis) across the plume and integrating the path concentration, we have

$w=\int_{y_{0}}^{y_{1}} u(y) \mathrm{d} y$,

where $w$ is now in units of $\mathrm{g} \mathrm{m}^{-1}$. The $y$ coordinate must be established from the measuring geometry. For static situations like this, the calculation is easily done by knowing the GPS positions of the camera and stack and the elevation of the camera. The field of view (FOV) of the camera can be determined from the following: $\Psi_{i}=2 \tan ^{-1}\left(\frac{X_{i}}{2 F}\right)$, where $X_{i}$ is the chip dimension, $i$ is horizontal or vertical dimension, and $F$ is the focal length of the lens. The physical dimension of a pixel in an image depends on the distance to the object and may be calculated from

$Z_{i}=\frac{2 d}{p_{i}} \tan ^{-1} \Psi_{i}$,

where $d$ is the distance to the object, $p_{i}$ is the number of pixels, and $Z_{i}$ is the pixel size (in $\mathrm{m}$ ). For the values given in Table 1, the angular field of view is

$\Psi_{h}=7.15^{\circ}$, 
Table 2. $\mathrm{SO}_{2}$ emission rates (fluxes) $\left(\mathrm{g} \mathrm{s}^{-1}\right)$ from seven ships measured within Kongsfjord, Ny Ålesund either steaming or at anchor. Passenger numbers are indicative only, it is not known whether the ships were at their carrying capacity. No information on the engines or their settings was available at the time of the measurements.

\begin{tabular}{lrrrl}
\hline Ship & $\begin{array}{r}\text { Gross displacement } \\
\text { (tons) }\end{array}$ & $\begin{array}{r}\text { Number of } \\
\text { passengers }\end{array}$ & $\begin{array}{r}\text { Emission range } \\
\left(\mathrm{g} \mathrm{s}^{-1}\right)\end{array}$ & Activity \\
\hline Expedition & 6336 & 120 & $\sim 11-14$ & Manoevering \\
Mona Lisa & 26678 & 450 & $\sim 2-4$ & At anchor \\
Vavilov & 6450 & 110 & $\sim 6-11$ & Manoevering \\
Polar Star & 4998 & 100 & $\sim 4-8$ & At anchor \\
Costa Magica & 102587 & 3470 & $\sim 10-18$ & Steaming \\
Columbus & 15000 & 423 & $\sim 10-15$ & Steaming \\
Nordstjernen & 2181 & 100 & $\sim 3-10$ & Manoevering \\
Prof. Multanovsky & 2140 & 52 & $\sim 2-8$ & At anchor \\
\hline
\end{tabular}

$\Psi_{v}=5.45^{\circ}$.

Given the apparent plume speed, obtained from the data or using ancillary measurements (e.g. local wind speed data), the emission rate, $s_{\mathrm{e}}$ is

$s_{\mathrm{e}}=w v_{p}$.

If the units of plume speed $\left(v_{\mathrm{p}}\right)$ are $\mathrm{ms}^{-1}$ and the units of $w$ are $\mathrm{g} \mathrm{m}^{-1}$ then the units of the emission rate are $\mathrm{g} \mathrm{s}^{-1}$. The plume tracking procedure was essentially a manual process: series of images were first inspected visually to identify regions of high contrast between plume and background in the image sequences. These were median filtered to reduce image speckle and then these regions in consecutive images were differenced to identity the plume movement. It can be seen that an advantage of using fast sampling imagery is that consecutive images can be analysed to determine small movements of the plume, at plume level, and hence emission rate $\left(\mathrm{g} \mathrm{s}^{-1}\right)$ can be estimated. This procedure was utilised here but because of the complication that the ships were often moving, not always in a fixed direction, and plume speed can only be estimated in the plane orthogonal to the camera viewing direction, results were best when the ships were close by and orthogonal to the camera. Accurate wind speed and direction data were available from a nearby meteorological station established for the measurement campaign at a height of $1.5 \mathrm{~m}$ above the surface, so these data could be used in the emission analysis with a height correction (see Sect. 3.7). When possible both methods were utilised.

\subsection{Distance calibration}

In order to check on the operation of the camera and to ensure the field of view calculations were accurate, measurements of the $\mathrm{SO}_{2}$ emissions from a nearby stack were made. The location of the stack (see Fig. 1) was approximately due south of site \#2 and $1.6 \mathrm{~km}$ distant. Since the camera elevation angle, the GPS position of the camera and stack are all known, the height of the stack determined from the images, in image pixels, could be checked against the known height of the stack.
Table 3. Main sources of error in the retrieval of $\mathrm{SO}_{2}$ path concentration and emission rate from the UV camera. Note that the errors due to visibility have not been included in the final error budget. In practice this error is difficult to characterise and so only data where the visibility is good have been used. Averaging of 10-20 frames is performed in the data analysis and this has the tendency to reduce errors due to noise and atmospheric variability.

\begin{tabular}{lrrr}
\hline Parameter & $\begin{array}{r}\text { Uncertainty } \\
1-\sigma\end{array}$ & $\begin{array}{r}\text { Impact } \\
\text { retrieval } \\
u(\mathrm{ppm} \mathrm{m})\end{array}$ & $\begin{array}{r}\text { Emission rate } \\
\text { error, } \sigma_{\mathrm{e}} \\
\left(\mathrm{g} \mathrm{s}^{-1}\right)\end{array}$ \\
\hline Calibration & \pm 4 counts & \pm 10 & \pm 3 \\
Reference profile & \pm 4 counts & \pm 10 & \pm 3 \\
Distance & $\pm 10 \mathrm{~m}$ & \pm 5 & \pm 1.5 \\
Ship speed & $\pm 0.2 \mathrm{~m} \mathrm{~s}^{-1}$ & - & \pm 1.5 \\
Wind speed & $\pm 1 \mathrm{~m} \mathrm{~s}^{-1}$ & - & \pm 2.5 \\
Visibility & -10 to -20 & -25 to -50 & -7 to -15 \\
\hline Total rms error & & \pm 15 & \pm 5 \\
\hline
\end{tabular}

This gave a pixel size of $0.15 \mathrm{~m}$ in close agreement with that expected $(0.148 \mathrm{~m})$.

\subsection{Wind speed}

Data from the JRC anemometer located at site \#2 were used as input to estimate the wind speed at plume height. A simple relation was used to extrapolate the wind at anemometer height to that at plume height. This is

$v(z)=v_{0}\left(\frac{z}{z_{0}}\right)^{a}$,

where $v_{0}$ is the wind speed at height $z_{0}$ and $a$ is an empirically determined constant, taken to be one-seventh (Garratt, 1972). The actual (apparent) plume speed must be determined from a combination of the wind speed (and direction) at plume height and the ship speed and direction: see Fig. 4 of Alföldy et al. (2013). The vector component is easy to determine from these speeds and directions, but the ship speed was unknown. Thus for all of the analyses the ship heading 

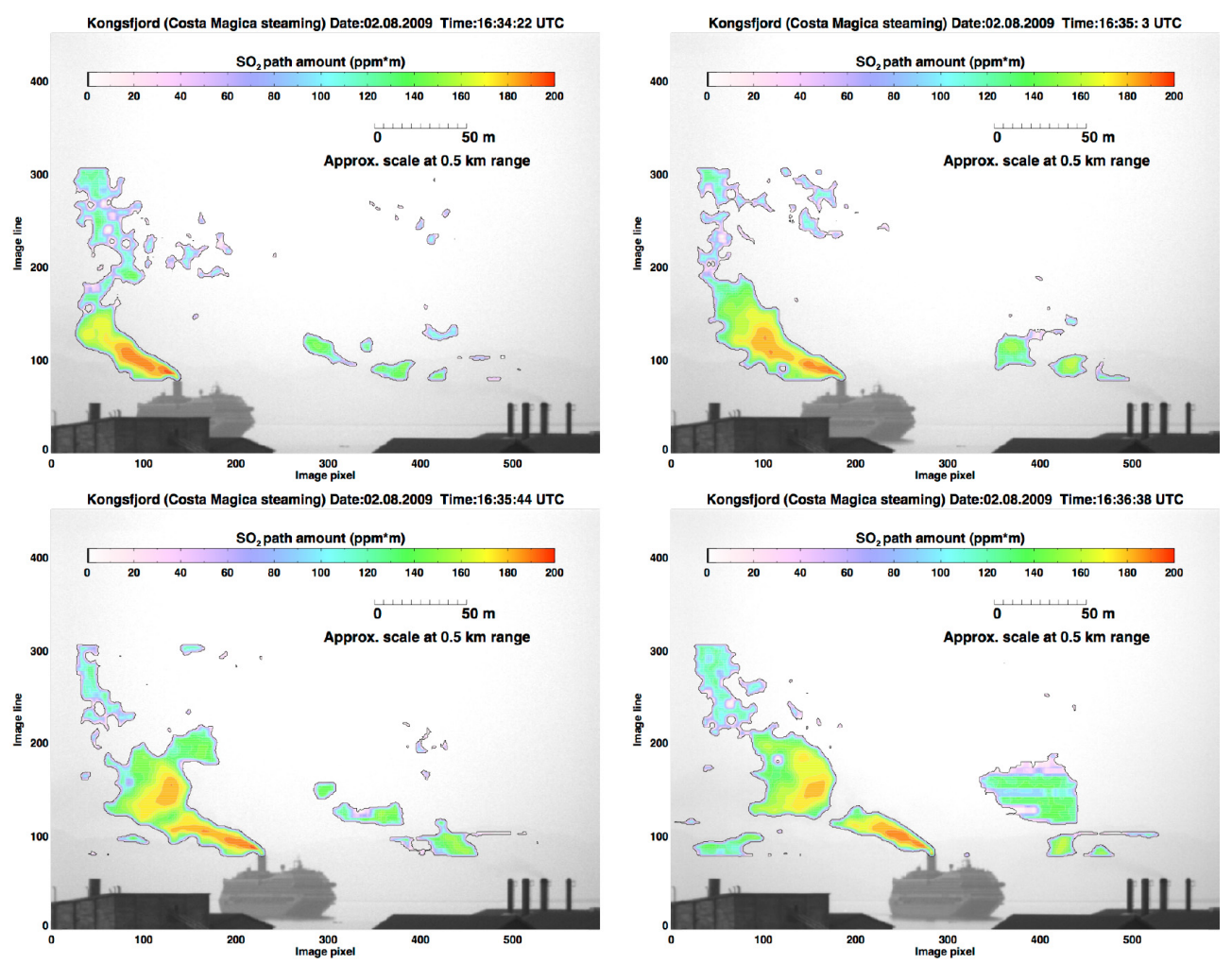

Fig. 7. $\mathrm{SO}_{2}$ path amounts retrieved from the UV camera for a cruise ship steaming into Kongsfjord. Ny Ålesund.

was assumed to be $298^{\circ}$ for ships leaving the port channel and $118^{\circ}$ for ships entering the port. The ship speed was estimated from the camera imagery by noting the time taken for the ship to pass across the camera. The accuracy of this measurement is very good provided the distance calibration is also good.

\section{Errors}

Table 3 lists the important sources of error in the retrieval of the concentration path and the emission rate. In this we assume a mean profile retrieval with: path concentration, $u=100 \mathrm{ppm} \mathrm{m}$, mean wind speed, $v_{\mathrm{w}}=8 \mathrm{~m} \mathrm{~s}^{-1}$, plume width/depth, $L=10 \mathrm{~m}$, ship speed, $v_{\mathrm{s}}=4 \mathrm{~m} \mathrm{~s}^{-1}$ for a ship $200 \mathrm{~m}$ away. These values give a mean emission rate of $\sim 30 \mathrm{~g} \mathrm{~s}^{-1}$. This analysis suggests that in good visibility conditions, the error is on the order of $\sim 20 \%$ in the emission rate and $\sim 15 \%$ in the concentration path. The ability to retrieve $\mathrm{SO}_{2}$ mass loading depends essentially on being able to achieve a high count difference between the plume and the background. This contrast in UV light is often better when the camera to plume distance is small $(<500-1000 \mathrm{~m})$. Thus one measure for visibility in the context of retrieving $\mathrm{SO}_{2}$ form UV cameras is the difference between the light intensity from the plume and the background nearby (either side of the plume). It should be stressed that these errors are probably the least expected as it is assumed that the camera calibration is stable, and more importantly that atmospheric conditions are benign, that is, visibility is good, the sky is bright and uniform (few clouds). It is also assumed that the plume is free of particulates. This assumption is likely to be wrong in most cases, so plumes that appeared "clean" in visible light were mostly considered. For some ships (e.g. the Stena line ferries), the plumes always appeared "dirty" and so these retrievals are biased towards higher emission rates. Soot in ship plumes is well known (Lack et al., 2009; Lack and Corbett, 2012; Buffaloe et al., 2014), and also known to be a strongly absorbing aerosol of visible and UV light (Bergstrom et al., 2002; Schnaiter et al., 2003). An estimate of the size of this effect is provided in the Appendix, where it is proposed that a second simultaneous camera measurement is made at a longer wavelength where $\mathrm{SO}_{2}$ no longer absorbs, but where black carbon (soot) does. The bias error incurred due to the effect of black carbon particulate absorption on the $\mathrm{SO}_{2}$ retrieval is linearly proportional to the black carbon mass loading. Plumes can vary greatly in their particulate content, depending on the engine, the type of fuel used and the engine load. Emission factors of light absorbing carbon reported by Lack et al. (2009) varied from $0.36-0.97 \mathrm{~g} \mathrm{~kg}^{-1}$ for different kinds of ships and different engines and engine loads.

Visibility can also drastically affect the performance of the retrieval because it depends on a contrast between the light from the plume and light from the background nearby. 
Table 4. $\mathrm{SO}_{2}$ path amounts and emission estimates from the UV camera for measurements on 18 September 2009.

\begin{tabular}{|c|c|c|c|c|c|c|c|c|c|c|}
\hline $\begin{array}{l}\text { Time } \\
\text { (LT) }\end{array}$ & Ship name & IMO & $\begin{array}{r}\text { Plume } \\
\text { height }(\mathrm{m})\end{array}$ & $\begin{array}{r}\text { Plume } \\
\text { width (m) }\end{array}$ & $\begin{array}{r}\text { Path concentration } \\
\qquad\left(\mathrm{g} \mathrm{m}^{-2}\right)\end{array}$ & $\begin{array}{r}\text { Error } \\
\left(\mathrm{g} \mathrm{m}^{-2}\right)\end{array}$ & $\begin{array}{r}\text { Emission } \\
\text { rate }\left(\mathrm{g} \mathrm{s}^{-1}\right)\end{array}$ & $\begin{array}{r}\text { Error } \\
\left(\mathrm{g} \mathrm{s}^{-1}\right)\end{array}$ & $\begin{array}{l}\text { Apparent plume } \\
\text { speed }\left(\mathrm{m} \mathrm{s}^{-1}\right)\end{array}$ & Distance \\
\hline $08: 38$ & Stena Hollandica & 9145176 & 18.5 & 10.0 & 0.195 & \pm 0.027 & 23.1 & \pm 4.1 & 11.7 & 1200 \\
\hline 08:57 & Aura & 9279716 & 8.0 & 3.0 & 0.617 & \pm 0.080 & 17.1 & \pm 3.4 & 9.6 & 120 \\
\hline 11:05 & BCL Iwona & 7000001 & 14.5 & 2.5 & 0.583 & \pm 0.079 & 13.7 & \pm 2.5 & 9.4 & 200 \\
\hline $11: 19$ & NS Concept & 9299707 & 18.0 & 8.0 & 0.369 & \pm 0.051 & 28.6 & \pm 4.9 & 9.6 & 600 \\
\hline $15: 35$ & NYK Cool & 9038323 & 22.0 & 10.0 & 1.570 & \pm 0.196 & 174.3 & \pm 34.9 & 11.0 & 400 \\
\hline $15: 35$ & NYK Cool & 9038323 & 20.0 & 9.0 & 1.491 & \pm 0.195 & 148.3 & \pm 29.7 & 10.9 & 400 \\
\hline $15: 35$ & NYK Cool & 9038323 & 19.5 & 8.0 & 1.535 & \pm 0.195 & 133.0 & \pm 27.9 & 10.8 & 400 \\
\hline $15: 47$ & OPDR Tanger & 9389306 & 20.0 & 7.0 & 0.098 & \pm 0.015 & 4.8 & \pm 1.0 & 7.3 & 600 \\
\hline $16: 14$ & Stena Britannica & 9235517 & 18.0 & 4.0 & 0.786 & \pm 0.110 & 29.6 & \pm 5.0 & 9.5 & 240 \\
\hline $16: 14$ & Stena Britannica & 9235517 & 17.0 & 2.0 & 0.673 & \pm 0.098 & 11.1 & \pm 1.8 & 9.5 & 240 \\
\hline 16:14 & Stena Britannica & 9235517 & 16.0 & 3.0 & 1.152 & \pm 0.147 & 33.6 & \pm 5.4 & 9.5 & 240 \\
\hline 16:14 & Stena Britannica & 9235517 & 17.0 & 1.8 & 0.771 & \pm 0.100 & 12.7 & \pm 2.3 & 9.5 & 240 \\
\hline $16: 56$ & Spaarnedijk & 9285457 & 16.0 & 2.7 & 0.445 & \pm 0.055 & 10.2 & \pm 2.0 & 8.3 & 300 \\
\hline 17:01 & Endeavour & 9312595 & 18.0 & 6.5 & 0.518 & \pm 0.068 & 32.6 & \pm 6.0 & 9.6 & 200 \\
\hline $17: 27$ & STX Ace II & 9443853 & 17.5 & 6.1 & 0.454 & \pm 0.064 & 23.3 & \pm 4.7 & 8.3 & 760 \\
\hline $17: 37$ & Geest Trader & 9110535 & 10.0 & 2.8 & 0.418 & \pm 0.059 & 7.5 & \pm 1.2 & 6.6 & 140 \\
\hline
\end{tabular}

Finally, errors in the emission rate are obviously strongly affected by estimation of the apparent wind speed. The UV camera has the attribute that, for the case of a ship plume travelling in a direction orthogonal to the camera's viewing direction (something that can often be achieved by moving the camera), the apparent plume speed can be determined directly from consecutive images by feature tracking. In cases where this cannot be done, errors in the wind speed (and direction) could lead to emission rate errors as large as $30 \%$.

\section{Results}

\subsection{SUVEX}

Emissions were measured as the ships entered, departed or remained at anchor within Kongsfjord. In all cases emissions were generally low (mean emission rates $\sim 10 \mathrm{~g} \mathrm{~s}^{-1}$ ); likely due to a combination of the low $\mathrm{S}$ content of the fuel used but also due to the low engine speeds. On occasion, ships were seen to emit black-coloured smoke (particulates) and in these circumstances the $\mathrm{SO}_{2}$ retrieval is highly uncertain as no corrections for absorption by smoke particles were made (but see the Appendix). The types of measurements are illustrated in the 4 panels of Fig. 7 for the cruise ship Costa Mag$i c a$ as it slowly entered Kongsfjord. The plots show $\mathrm{SO}_{2}$ path amounts (also referred to as path concentrations or concentration multiplied by path length) in units of $\mathrm{ppm} \mathrm{m}^{1}$. Each panel is separated in time by about $30 \mathrm{~s}$. Retrievals are compromised by contrast changes in the background light due to reflections off the ship, buildings and other objects. Consequently no retrievals were attempted below a limiting height, indicated in the plots by the horizontal line. The emissions from the single funnel on the ship are clearly evident and sequences of images reveal that the retrievals are robust and

\footnotetext{
${ }^{1}$ At S.T.P. $100 \mathrm{ppm} \mathrm{m}=0.262 \mathrm{~g} \mathrm{~m}^{-2}$.
}

consistent. The $\mathrm{SO}_{2}$ emissions appearing ahead of the ship are due to emissions from the Ny Allesund power plant and qualitative analysis of the imagery shows a small plume emanating from the third stack in the row of four (counting from the left). Ships at anchor or manoeuvring slowly within the fjord also emitted $\mathrm{SO}_{2}$ and some examples are shown in Fig. 8. The lower panels reveal another limitation in obtaining retrievals from a single-filter UV camera system as the UV reflected light from the mountains in the background cannot be properly accounted for; the horizontal line shows the limiting height below which retrievals were not made. On these panels and in the panels of Fig. 7, a rough scale is shown for a notional object at a distance of $0.5 \mathrm{~km}$ from the camera. With a single camera it is not possible to resolve distances and it is impossible to discern whether the ship plumes are moving in the direction of the camera or in the opposite direction. This is another limitation that suggests automated quantitative calculation of ship emissions will be difficult. Finally, in Fig. 9 and Table 2, emission rates determined by tracking features within sequences of images are presented. The emission rates over quite short intervals (minutes) are easily determined by the analysis procedure and in all cases were low, $<20 \mathrm{~g} \mathrm{~s}^{-1}$. In the case of the SS Vavilov the mean emission rate is $8.5 \pm 2.6 \mathrm{~g} \mathrm{~s}^{-1}$.

\subsection{SIRENAS-R}

Distances to the ships and other targets are needed in order to estimate emission rates, since most of the ships were at sea and moving, and GPS data were not obtained, so only approximate values are given (see Fig. 1). The error in estimating the distances is assumed to be about $10-20 \mathrm{~m}$, which translates to an error in the emission rate of 5-10\%.

The main results are provided in Table 4 and as a series of plots, in the order: (a) a photograph of the ship in the visible, (b) a UV image of the ship and its plume, and (c) 

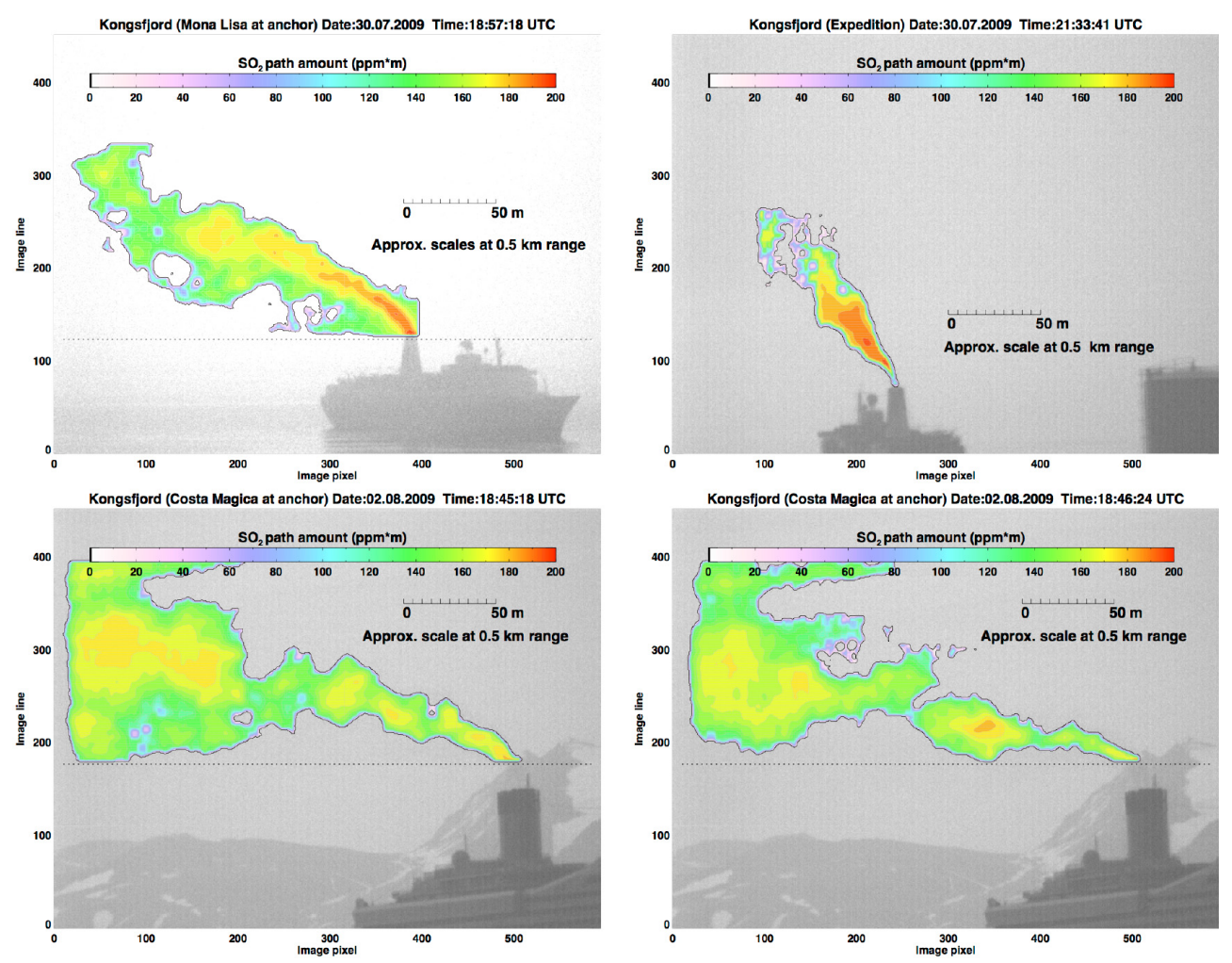

Fig. 8. $\mathrm{SO}_{2}$ path amounts retrieved from the UV camera for three different vessels in Kongsfjord at anchor or slowly manoeuvering.

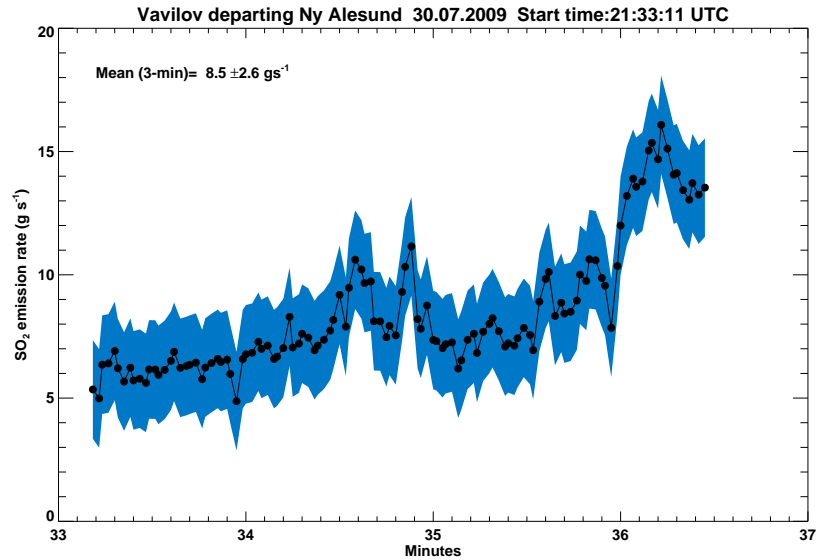

Fig. 9. $\mathrm{SO}_{2}$ emission rate for the $\mathrm{SS}$ Vavilov. The shaded region (in blue) represents the standard deviation of measurements averaged over $\sim 1 \mathrm{~s}$.

vertical profiles of the camera digital counts and the retrieved profile of the concentration path (in units of ppm m). The main parameters either retrieved or input are provided on the right-hand side panel of the profile plot. Measurements were made over several days, but atmospheric conditions were not always benign and the best data were obtained on 17 and 18 September, 2009. Approximately 50 sets of measurements were made, sometimes on the same ship, including several cases where the ship was at anchor or manoeuvring near a dock. A summary table (Table 4) is included showing all results for 18 September 2009 . Note that with only one camera and filter it is not possible to eliminate all types of interference. Hence in many of the plots the profiles are truncated at the lower levels to avoid anomalies due to hard objects (e.g. parts of the ships, land, trees and fixed objects). The main parameters estimated are the $\mathrm{SO}_{2}$ path amount and the emission rate.

Other results and inter comparisons are provided in Balzani Lööv et al. (2013). Generally, the UV camera overestimates the emissions by as much as $50 \%$ in some cases but on average they agree with independent measurements at the level of 10-20\%. The overestimation is due, in large part, to the presence of particulates in the ship plumes which reduce the UV signal suggesting greater $\mathrm{SO}_{2}$ and hence larger emission rate. The speed of the ships has also been neglected and this leads to errors in the estimation of emission rates, that in principle may be of either sign - underestimation or overestimation. This error may be significant because the ships, although moving slowly as they enter the harbour $\left(<2 \mathrm{~m} \mathrm{~s}^{-1}\right)$ may still, in the worst case impart an emission rate error directly proportional to $\left\|v_{\mathrm{w}}-v_{\mathrm{s}}\right\| /\left\|v_{\mathrm{w}}\right\|$. To illustrate the measurement methodology, four case studies are provided. 

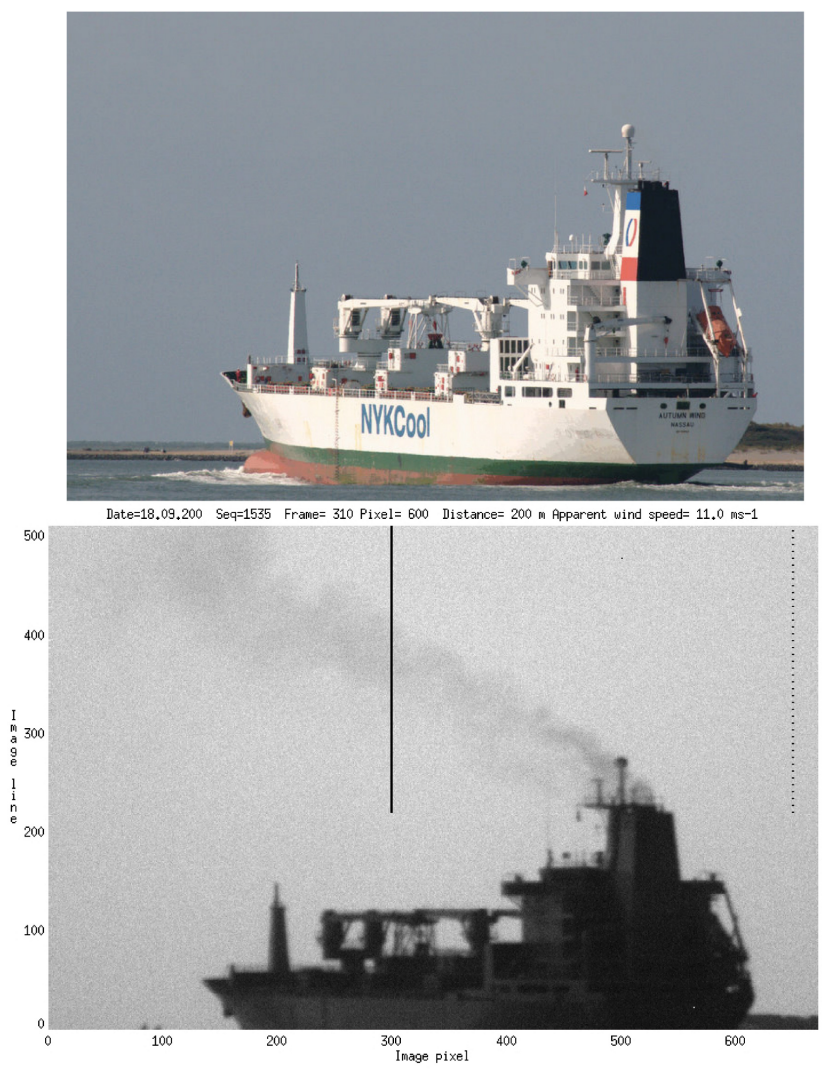

Fig. 10. Top: visible image of the NYK Cool (IMO 9038323). Bottom: UV image of the same ship. The black line shows the location of the vertical transect through the plume; the dashed line shows the location of the reference vertical profile.
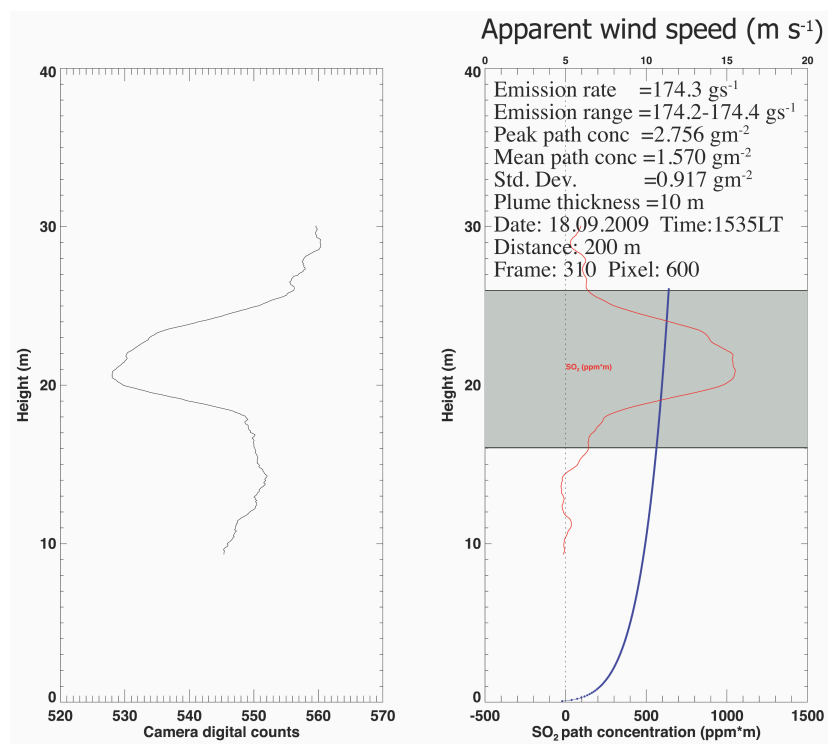

Fig. 11. $\mathrm{SO}_{2}$ path concentration $(u$, in ppm m) for NYK Cool

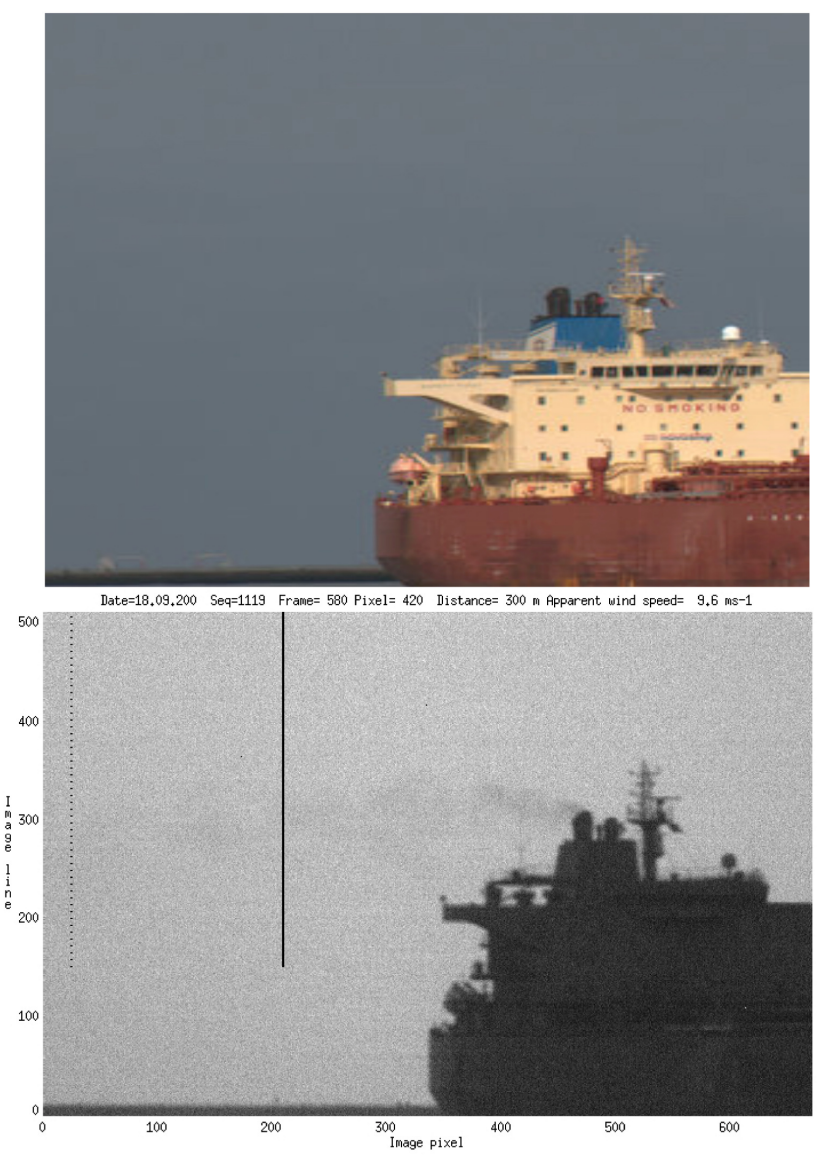

Fig. 12. Top: visible image of NS Concept (IMO 9299692) under steam into Hoek van Holland. Bottom: UV image of the same ship. The black line shows the location of the vertical transect through the plume; the dashed line shows the location of the reference vertical profile.

\subsubsection{NYK Cool}

NYK Cool operates a fleet of about 30 ships specialising in the transport of perishable items, so-called "reefers" (refrigeration containers). The particular vessel monitored in Rotterdam harbour is registered with IMO 9038323 (Autumn wind) and has a length of $158 \mathrm{~m}$, a breadth of $24 \mathrm{~m}$ and gross tonnage of $13.077 \mathrm{kt}$. There is just one main diesel generator engine of $2000 \mathrm{HP}$ and $700 \mathrm{RPM}$. The ship was monitored on 18 September 2009 at steam from a distance of approximately $200 \mathrm{~m}$ in a wind that was strong enough to cause the ships plume to travel in the direction of the ships motion (Fig. 10). A vertical transect through the plume was used to calculate the $\mathrm{SO}_{2}$ path concentrations and emission rates. The results are summarised in Table 4 and an example of the vertical profile of $\mathrm{SO}_{2}$ path concentration is shown in Fig. 11. The emission rates derived are the highest measured, in one case exceeding $170 \mathrm{~g} \mathrm{~s}^{-1}$. There were no visible signs of particulates in this plume, visibility was good and the distance to the ship was not large so the reason for the high emission 

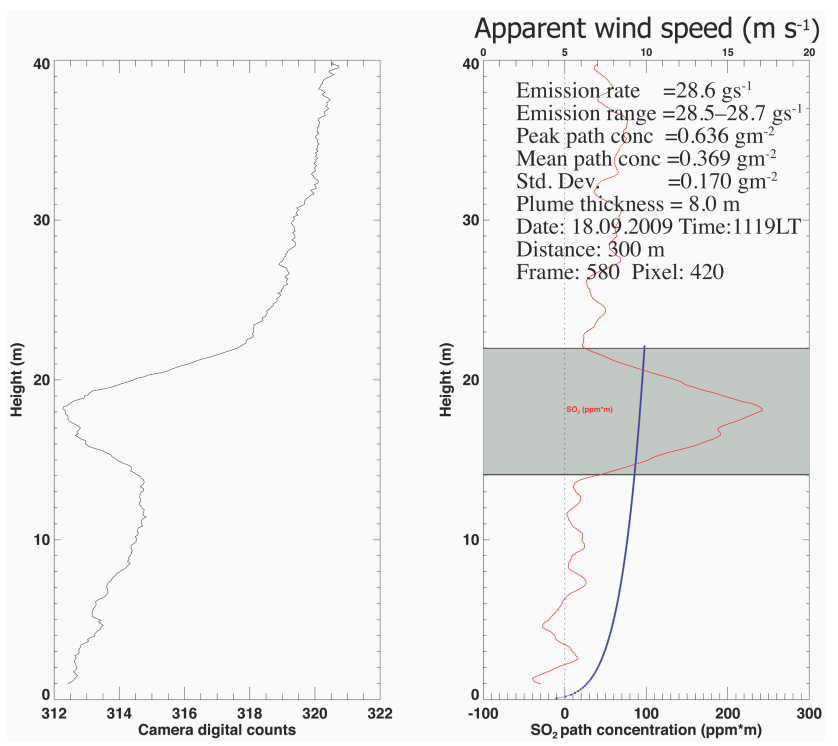

Fig. 13. $\mathrm{SO}_{2}$ path concentration $(u$, in ppm $\mathrm{m})$ for the NS Concept.
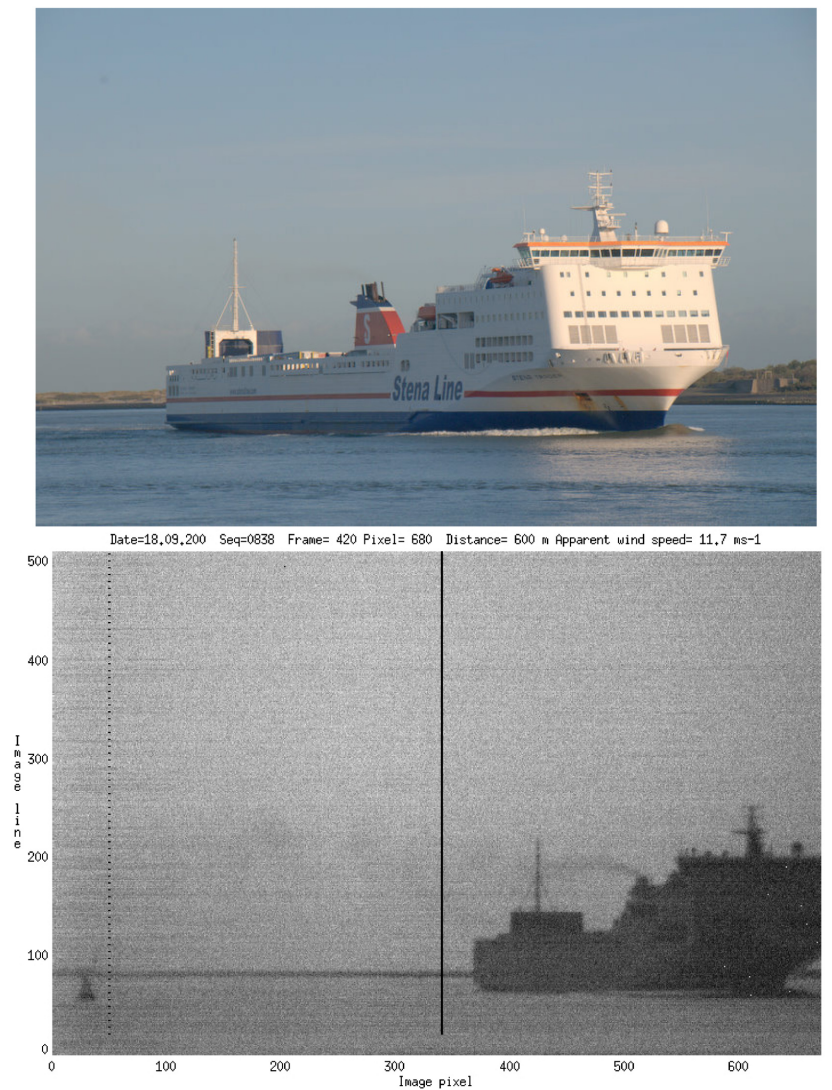

Fig. 14. Stena Hollandica under steam. Top: Visible photograph. Bottom: UV image of the same ship. The black line shows the location of the vertical transect through the plume; the dashed line shows the location of the reference vertical profile.
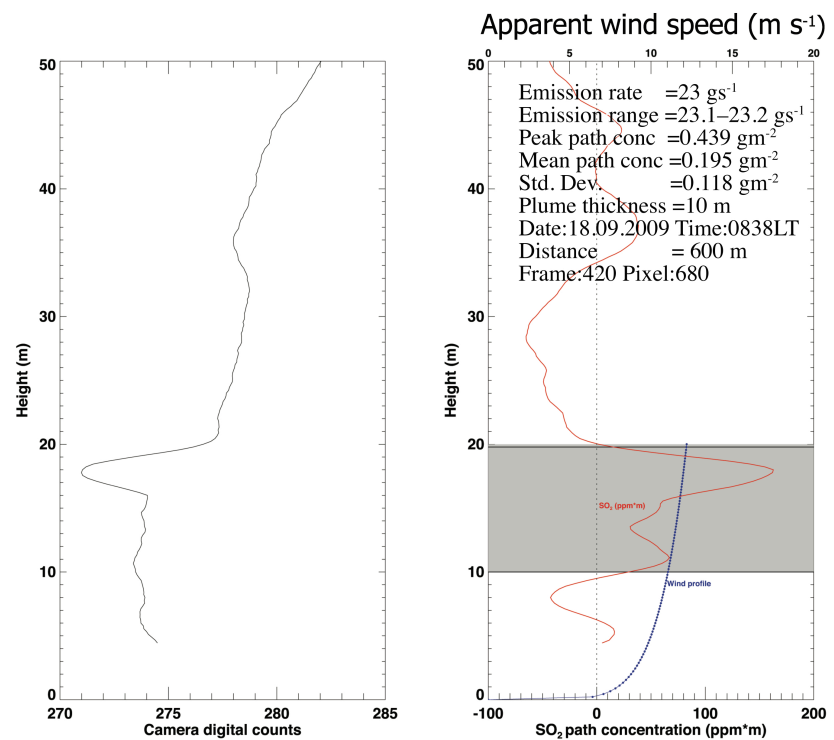

Fig. 15. $\mathrm{SO}_{2}$ path concentration $(u$, in ppm m) for the Stena Hollandica.

rates cannot be easily assigned to measurement conditions. A possible source of overestimation in this case could be due to an overestimate of the apparent wind speed. Since the plume travelled in the direction of ship travel, and the ship speed was not known it is possible that the apparent wind speed has been overestimated. The reported average speed for Autumn wind is 11.5 knots $\left(\sim 6 \mathrm{~m} \mathrm{~s}^{-1}\right)$; subtracting this component from the wind speed would result in emission estimates of about half the values given in Table 4 for NYK Cool. Even so, the emission rates are still quite high $\left(\sim 70-90 \mathrm{~g} \mathrm{~s}^{-1}\right)$, as are the path concentrations.

\subsubsection{NS Concept}

The NS Concept (IMO 9299692) is a large crude oil tanker with a gross tonnage of $57.248 \mathrm{kt}$, a length of $244 \mathrm{~m}$ and breadth of $42 \mathrm{~m}$. A photograph and UV image of the ship are shown in Fig. 12 and retrieval results shown in Fig. 13. The emission rates determined were in the range $20-30 \mathrm{~g} \mathrm{~s}^{-1}$ which appears to be reasonable for a ship of this size, with an average speed of just under 10 knots.

\subsubsection{Stena Hollandica}

The Stena Hollandica (IMO 9145176) is a super ferry (length $240 \mathrm{~m}$, gross displacement $51.837 \mathrm{kt}$ ) that travels from Hoek van Holland to Harwich, UK on a daily basis. There are four main engines generating $33600 \mathrm{~kW}$ of power. UV images were acquired on several days as the Stena Hollandica entered and left the port and also as it manoeuvred at dock. Distance to the ship varied from $500 \mathrm{~m}$ to over $2 \mathrm{~km}$ and the mean emission was found to be $23.1 \pm 4.1 \mathrm{~g} \mathrm{~s}^{-1}$. The apparent plume speed (combination of the true wind speed and 

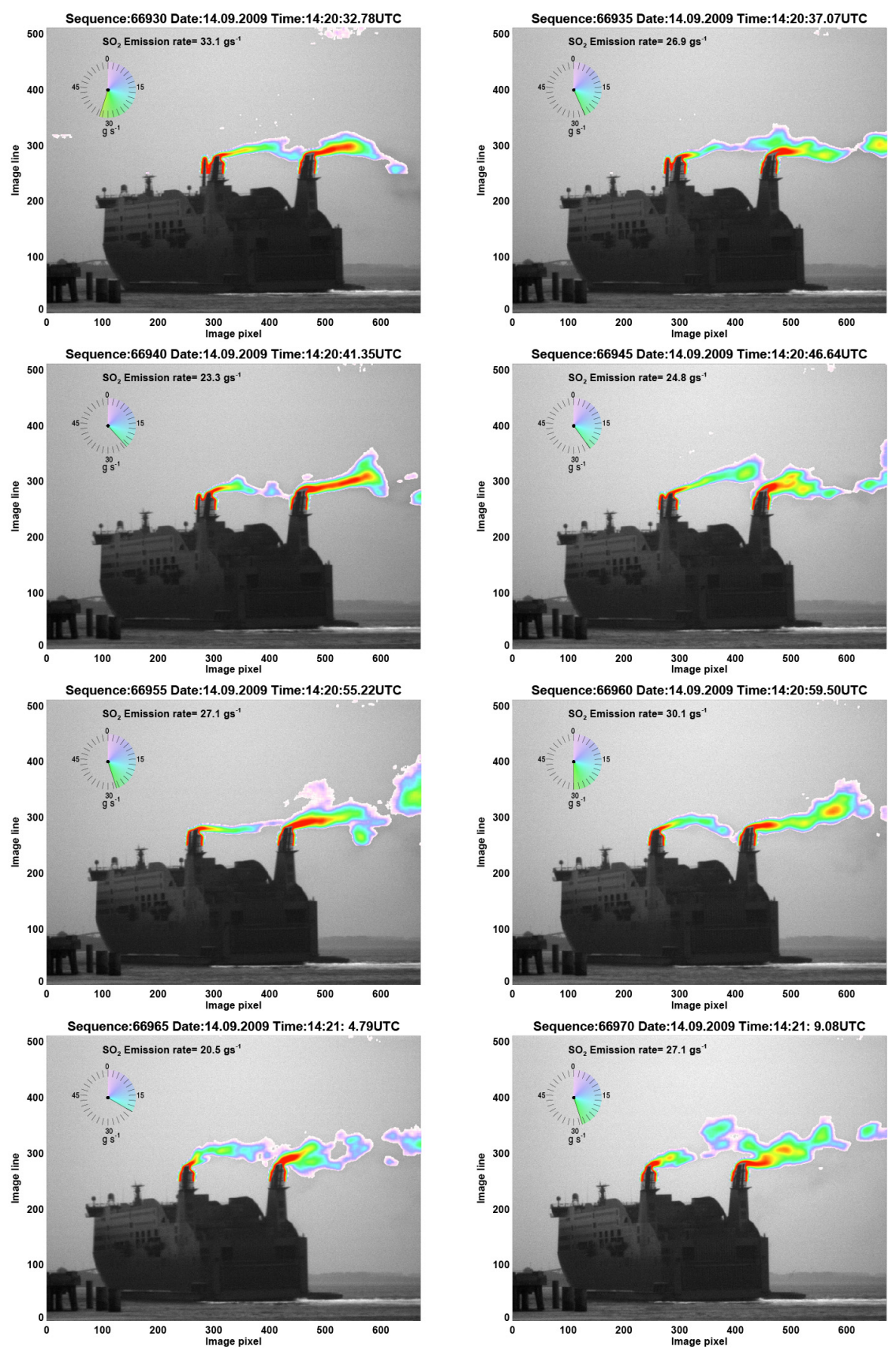

Fig. 16. Emission rate estimates from the UV camera or the Stena Hollandica manoeuvring at dock on 14 September 2009 . Images are between 5-10 s apart from a sequence acquired at $1 \mathrm{~s}$ intervals.

ship speed, measured from the perspective of the UV camera axis) was $\sim 11 \mathrm{~m} \mathrm{~s}^{-1}$. Figure 14 shows visible and UV images of the ferry as it was steaming into the port and and Fig. 15 shows an example vertical profile.

\subsubsection{Stena Hollandica - at dock}

Data were also captured when the ferry was at dock. In this case the ferry may be considered as approximately stationary, so that any errors in the emission rate calculation are due to errors in the estimation of the $\mathrm{SO}_{2}$ path concentration. A sequence of retrievals is shown in Fig. 16. The emissions are larger than independent measurements (by up to a factor of two) and are likely to be biased high because of particulates in the plume that have not been corrected for. Her sister ferry, Stena Britannica (IMO 9419175) with smaller length and less powerful engines gave emission rates from $11-33 \mathrm{~g} \mathrm{~s}^{-1}$, that also appear to be biased high. 


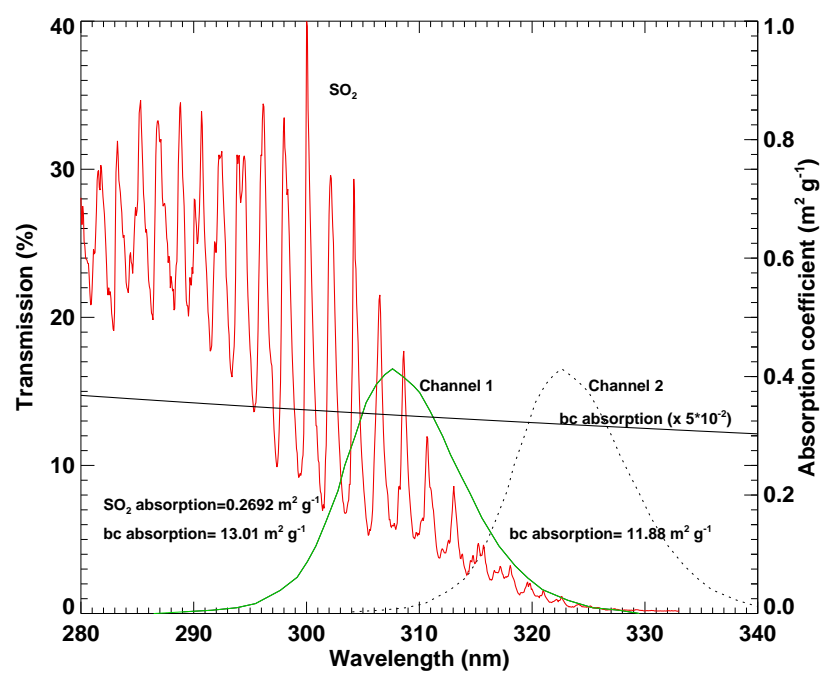

Fig. 17. Channel filter responses, black carbon (bc) absorption and laboratory measured $\mathrm{SO}_{2}$ absorption. The channel-averaged values of the mass absorption coefficient for $\mathrm{SO}_{2}$ and $\mathrm{BC}$ are provided on the plot.

The emission rate in the sequence of eight images has been determined using a constant near-surface wind speed of $3 \mathrm{~m} \mathrm{~s}^{-1}$ and a ship speed of $1 \mathrm{~m} \mathrm{~s}^{-1}$. The Stena ferry was manoeuvring near the dock and the engine power was variable which has resulted in a highly variable emission rate of between $20-60 \mathrm{~g} \mathrm{~s}^{-1}$. These are among the highest emission rates measured in the Hoek van Holland channel and it is likely that they are overestimations, due to the particulates in the ship plume. Hobbs et al. (2000) estimated $\mathrm{SO}_{2}$ emission rates of $3-12 \mathrm{~g} \mathrm{~s}^{-1}$ for four sea-going vessels. Isakson et al. (2001) estimate the $\mathrm{SO}_{2}$ concentration in a ship plume in Göteborg harbour, Sweden to be $\sim 4.5 \mu \mathrm{g} \mathrm{m}^{-3}$, which corresponds to path amounts of $\sim 0.1 \mathrm{~g} \mathrm{~m}^{-2}$ for path lengths of $\sim 100 \mathrm{~m}$, compared to values as high as $0.2 \mathrm{~g} \mathrm{~m}^{-2}$ for path lengths of $10 \mathrm{~m}$ measured in this study.

\section{Conclusions}

Ship plume measurements from an innovative, fast-sampling single-filter UV imaging camera have been made at Kongsfjord, Svalbard, and at Rotterdam harbour (Hoek van Holland). A simple scheme was developed to rapidly assess the path amounts (concentration $\times$ plume depth in $\mathrm{ppm} m$ or $\mathrm{g} \mathrm{m}^{-2}$ ) and emissions determined either from the camera imagery itself or by using a surface level wind speed and a model of its variation with height in the first few $100 \mathrm{~m}$ of the boundary layer. The camera is able to detect plumes and estimate emissions of $\mathrm{SO}_{2}$ but with limited accuracy. The purpose of the experiment was to assess the usefulness and reliability of a UV camera system to monitor ship emissions as an aid to estimate the $\mathrm{S}$ content of the fuel used. A comparison with other independent measurements of ship plumes during the experiment by Balzani Lööv et al. (2013) show that of four different techniques used, the UV camera gives highest emissions. The UV camera retrieved twice the emission rates of a scanning lidar; however, in the case of the Stena Line ferries the UV camera measurements are very close to the lidar measurements and are in excellent agreement with UV DOAS and a model calculation for the Stena Hollandica (see Figs. 9 and 10 of Balzani Lööv et al., 2013). Currently the system is not able to be used reliably for this purpose as it generally overestimates the emissions, mostly due to the presence of particulates in the plumes (which could not be corrected for). One possible way to alleviate this effect is to make measurements at other wavelengths, as is done in the DOAS technique and correct for the absorption by particles. Thus a camera combined with a spectrometer might be one way to overcome this problem. Another way might be to incorporate more filters with the camera, for example, by adding a filter wheel. This approach has the advantage of maintaining full image resolution but will be slower (typically $0.1-1 \mathrm{~Hz}$ ) and because ships under steam are moving targets, collocation of images at different wavelengths may be problematic. A third more attractive approach is to use two or more cameras with different filters working simultaneously (e.g. Kantzas et al., 2010), or preferably a single, dual-path CCD operating at two wavelengths thereby maximising coincidence and sampling frequency, and eliminating inter-calibration of CCDs. Improved, realistic radiative transfer can also be implemented. Even after overcoming these mostly technical challenges, there remains the problem of relating the $\mathrm{SO}_{2}$ emissions to fuel $\mathrm{S}$ content. In order to do that, information on the ships' engines is needed or a simultaneous measurement of the $\mathrm{CO}_{2}$ emissions is required. The $\mathrm{SO}_{2}$ camera may therefore best be suited as a complementary technology used in conjunction with chemical sniffers, UV DOAS, active sensing (lidar) and/or a model of ship engine performance. 


\section{Appendix A}

\section{Correction for soot}

For a single-filter camera as described here, it is not possible to correct for the effects of interfering species in the plume, including absorbing particulates. This is a limitation of the camera utilised but technically this problem can be overcome by using a second filter or preferably a second camera. Such a system has been developed and tested but a complete description of this system is beyond the scope of this paper and will be reported in a later paper. However, in view of the impact of particulates on the present results it is important to describe the correction procedure to better appreciate how the limitations of the single-filter camera may be overcome.

The correction is based on the use of a second channel at a longer wavelength $(\sim 325 \mathrm{~nm})$ where $\mathrm{SO}_{2}$ is much less absorbing and indeed negligible in the case of ship emissions, with very low $\mathrm{SO}_{2}$ contents. Buffaloe et al. (2014) report new measurements of the mass absorption coefficient for the fresh black carbon component in ship plumes and derive an equation for its wavelength dependence. Soot absorbs light; more strongly in the UV region and the "fresh" black carbon is the major component of soot responsible. Other work (Schnaiter et al., 2003) suggests the absorption coefficient for soot has a value of $12-16 \mathrm{~m}^{2} \mathrm{~g}^{-1}$ in the ultraviolet region $(\lambda \sim 280$ $320 \mathrm{~nm}$ ). Figure 17 shows the placement of the second channel with respect to the first together with a laboratory measured $\mathrm{SO}_{2}$ absorption spectrum and the mass absorption for fresh black carbon according to Buffaloe et al. (2014) (see also Eq. 13).

The correction procedure assumes that the light absorption in the second channel (channel 2 on Fig. 17) is predominantly due to particulates (black carbon), while the absorption in the first channel is due to both $\mathrm{SO}_{2}$ and light absorbing particulates. Employing the BBL law for the channel with central wavelength $\lambda \sim 325 \mathrm{~nm}$, the mass loading $\left(\mathrm{g} \mathrm{m}^{-2}\right)$ of black carbon (bc) is

$m_{\mathrm{bc}}=-\frac{1}{k_{\mathrm{bc}}(325)} \ln \left[\frac{I(325)}{I_{0}(325)}\right]$,

where the intensities $I(325), I_{0}(325)$ are measured after and before the light enters the plume and it is understood that a dark current value has been removed. At the wavelength where both $\mathrm{SO}_{2}$ and black carbon absorb, the mass loading of the black carbon is

$m_{\mathrm{bc}}=-\frac{1}{k_{\mathrm{bc}}(308)} \ln \left[\frac{I(308)}{I_{0}(308)}.\right]$
Since the mass loading of black carbon must be the same,

$\ln \left[\frac{I(308)}{I_{0}(308)}\right]=\frac{k_{\mathrm{bc}}(308)}{k_{\mathrm{bc}}(325)} \ln \left[\frac{I(325)}{I_{0}(325)}\right]$.

Thus measurements of the intensities at $\lambda \sim 325 \mathrm{~nm}$ when combined with knowledge of the mass absorption coefficients of black carbon, can be used to estimate the logarithm of the ratio of intensities at the first wavelength $(\lambda \sim 308 \mathrm{~nm})$, where $\mathrm{SO}_{2}$ is also absorbing. An estimate of the corrected $\mathrm{SO}_{2}$ mass loading is as follows:

$$
\begin{aligned}
m_{\mathrm{SO}_{2}} & = \\
& -\frac{1}{k_{s}(308)}\left\{\ln \left[\left(\frac{I^{\prime}(308)}{I_{0}^{\prime}(308)}\right) /\left(\frac{I(325)}{I_{0}(325)}\right)^{\kappa}\right]\right\},
\end{aligned}
$$

where $\kappa=\frac{k_{\mathrm{bc}}(308)}{k_{\mathrm{bc}}(325)}$, and $I^{\prime}(308)$ and $I_{0}^{\prime}(308)$ denote the measured light intensities exiting and entering the ship plume, without correction for soot. Buffaloe et al. (2014) suggest that the mass absorption coefficient for bc at wavelength $\lambda$ may be calculated from

$k_{\mathrm{bc}}(\lambda)=k_{\mathrm{bc}}(550)\left(\frac{550}{\lambda}\right)$,

where $k_{\mathrm{bc}}(550)=7.5 \pm 1.5 \mathrm{~m}^{2} \mathrm{~g}^{-1}$. It follows that $\kappa \sim$ $\lambda_{2} / \lambda_{1} \sim 1.055$ for the two wavelengths used. Bergstrom et al. (2002) have reported measurements of the absorption coefficient for small particles of black carbon and also found a $\lambda^{-1}$ dependence. Inspection of Fig. 2 of Schnaiter et al. (2003) gives $\kappa \sim 1.064$ for Diesel soot in good agreement with the parameterisation above. The magnitude of the correction for soot depends on the amount of black carbon, which can be substantial, but unfortunately particulate measurements were not made during the SIRENAS-R campaign. According to the procedure outlined here, the correction depends linearly on the bc mass loading. Diesch et al. (2012) report simultaneous measurements of bc and $\mathrm{SO}_{2}$ from 139 ships leaving the port of Hamburg, Germany. The average values measured for bc were $0.15 \pm 0.17 \mathrm{~g} \mathrm{~kg}^{-1}$-fuel, compared to that for $\mathrm{SO}_{2}$ of $7.7 \pm 6.7 \mathrm{~g} \mathrm{~kg}^{-1}$-fuel. Thus the $\mathrm{bc}$ mass loading could be between $2 \%$ and $30 \%$ of the $\mathrm{SO}_{2}$ mass loading, leading to significant bias if not corrected. Finally, it is noted here that the dual wavelength camera system (two filters, one or two cameras) in principle can be used to determine the mass loading of black carbon and $\mathrm{SO}_{2}$ simultaneously. 
Acknowledgements. The Joint Research Centre (JRC), Ispra, Italy is thanked for financial support for the SIRENAS-R and SIRENAS-G campaigns. The Norwegian Polar Institute provided funding and logistical support during the SUVEX campaign. Jacob Balzani Lööv, Balint Alföldy and Jens Hjorth (JRC) are thanked for logistical support during the SIRENAS campaigns. NILU scientists Kerstin Stebel, Franck Dauge, and Rolf Haugen provided help and advice in the development of the UV camera system. Are Bäcklund (NILU) assisted at Ny Allesund during the SUVEX campaign. I am especially grateful to the three referees who have helped me improve the paper with their suggestions. Christoph Kern is particularly thanked for his careful reading of the Discussion paper and for his insightful comments. Andreas Richter is thanked for his patient editorial work on the paper.

Edited by: A. Richter

\section{References}

Alföldy, B., Lööv, J. B., Lagler, F., Mellqvist, J., Berg, N., Beecken, J., Weststrate, H., Duyzer, J., Bencs, L., Horemans, B., Cavalli, F., Putaud, J.-P., Janssens-Maenhout, G., Csordás, A. P., Van Grieken, R., Borowiak, A., and Hjorth, J.: Measurements of air pollution emission factors for marine transportation in SECA, Atmos. Meas. Tech., 6, 1777-1791, doi:10.5194/amt-61777-2013, 2013.

Balzani Lööv, J. M., Alfoldy, B., Beecken, J., Berg, N., Berkhout, A. J. C., Duyzer, J., Gast, L. F. L., Hjorth, J., Jalkanen, J.-P., Lagler, F., Mellqvist, J., Prata, F., van der Hoff, G. R., Westrate, H., Swart, D. P. J., and Borowiak, A.: Field test of available methods to measure remotely $\mathrm{SO}_{2}$ and $\mathrm{NO}_{\mathrm{x}}$ emissions from ships, Atmos. Meas. Tech. Discuss., 6, 9735-9782, doi:10.5194/amtd-6-97352013, 2013.

Bergstrom, R. W., Russell, P. B., and Hignett, P.: Wavelength dependence of the absorption of black carbon particles: Predictions and results from the TARFOX experiment and implications for the aerosol single scattering albedo, J. Atmos. Sci., 59, 567-577, 2002.

Berresheim, H. and Jaeschke, W.: The contribution of volcanoes to the global atmospheric sulfur budget, J. Geophys. Res.-Oceans, 88, 3732-3740, 1983.

Bluth, G., Shannon, J., Watson, I., Prata, A., and Realmuto, V.: Development of an ultra-violet digital camera for volcanic $\mathrm{SO}_{2}$ imaging, J. Volcanol. Geoth. Res., 161, 47-56, 2007.

Bogumil, K., Orphal, J., Homann, T., Voigt, S., Spietz, P., Fleischmann, O., Vogel, A., Hartmann, M., Kromminga, H., Bovensmann, H., Frerick, J., and Burrows, J. P.: Measurements of molecular absorption spectra with the SCIAMACHY pre-flight model: Instrument characterization and reference data for atmospheric remote-sensing in the $230-2380 \mathrm{~nm}$ region, J. Photochem. Photobiol. A, 157, 167-184, 2003.

Buffaloe, G. M., Lack, D. A., Williams, E. J., Coffman, D., Hayden, K. L., Lerner, B. M., Li, S.-M., Nuaaman, I., Massoli, P., Onasch, T. B., Quinn, P. K., and Cappa, C. D.: Black carbon emissions from in-use ships: a California regional assessment, Atmos. Chem. Phys., 14, 1881-1896, doi:10.5194/acp-14-18812014, 2014.

Corbett, J. J. and Fischbeck, P.: Emissions from ships, Science, 278, 823-824, 1997.
Corbett, J. J. and Koehler, H. W.: Updated emissions from ocean shipping, J. Geophys. Res.-Atmos., 108, 4650, doi:10.1029/2003JD003751, 2003.

Dalton, M. P., Watson, I. M., Nadeau, P. A., Werner, C., Morrow, W., and Shannon, J. M.: Assessment of the UV camera sulfur dioxide retrieval for point source plumes, J. Volcanol. Geoth. Res., 188, 358-366, 2009.

Diesch, J.-M., Drewnick, F., Klimach, T., and Borrmann, S.: Investigation of gaseous and particulate emissions from various marine vessel types measured on the banks of the Elbe in Northern Germany, Atmos. Chem. Phys., 13, 3603-3618, doi:10.5194/acp-133603-2013, 2013.

Garratt, J.: The Atmospheric Boundary Layer, Cambridge Univ. Press, 1972.

Graf, H.-F., Feichter, J., and Langmann, B.: Volcanic sulfur emissions: Estimates of source strength and its contribution to the global sulfate distribution, J. Geophys. Res.-Atmos., 102, 10727-10738, 1997.

Hobbs, P. V., Garrett, T. J., Ferek, R. J., Strader, S. R., Hegg, D. A., Frick, G. M., Hoppel, W. A., Gasparovic, R. F., Russell, L. M., Johnson, D. W., O’Dowd, C., Durkee, P. A., Nielsen, K. E., and Innis, G.: Emissions from ships with respect to their effects on clouds, J. Atmos. Sci., 57, 2570-2590, 2000.

Isakson, J., Persson, T., and Selin Lindgren, E.: Identification and assessment of ship emissions and their effects in the harbour of Göteborg, Sweden, Atmos. Environ., 35, 3659-3666, 2001.

Kantzas, E. P., McGonigle, A., Tamburello, G., Aiuppa, A., and Bryant, R. G.: Protocols for UV camera volcanic $\mathrm{SO}_{2}$ measurements, J. Volcanol. Geoth. Res., 194, 55-60, 2010.

Kern, C.: Spectroscopic measurements of volcanic gas emissions in the ultra-violet wavelength region, PhD Thesis, 2009.

Kern, C., Deutschmann, T., Vogel, L., Wöhrbach, M., Wagner, T., and Platt, U.: Radiative transfer corrections for accurate spectroscopic measurements of volcanic gas emissions, B. Volcanol., 72, 233-247, 2010.

Kern, C., Werner, C., Elias, T., Sutton, A. J., and Lübcke, P.: Applying UV cameras for $\mathrm{SO}_{2}$ detection to distant or optically thick volcanic plumes, J. Volcanol. Geoth. Res., 262, 80-89, 2013.

Kullmer, R. and Demtrōder, W.: Vibronic coupling in $\mathrm{SO}_{2}$, and its influence on the rotational structure of the bands in the 300$330 \mathrm{~nm}$ region, Chem. Phys., 92, 423-433, 1985.

Lack, D. A. and Corbett, J. J.: Black carbon from ships: a review of the effects of ship speed, fuel quality and exhaust gas scrubbing, Atmos. Chem. Phys., 12, 3985-4000, doi:10.5194/acp-12-39852012, 2012.

Lack, D. A., Corbett, J. J., Onasch, T., Lerner, B., Massoli, P., Quinn, P. K., Bates, T. S., Covert, D. S., Coffman, D., Sierau, B., Herndon, S., Allan, J., Baynard, T., Lovejoy, E., Ravishankara, A. R. and Williams, E.: Particulate emissions from commercial shipping: Chemical, physical, and optical properties, J. Geophys. Res.-Atmos., 114, D00F04, doi:10.1029/2008JD011300, 2009.

Lübcke, P., Bobrowski, N., Illing, S., Kern, C., Alvarez Nieves, J. M., Vogel, L., Zielcke, J., Delgado Granados, H., and Platt, U.: On the absolute calibration of $\mathrm{SO}_{2}$ cameras, Atmos. Meas. Tech., 6, 677-696, doi:10.5194/amt-6-677-2013, 2013.

McElhoe, H. B. and Conner, W. D.: Remote measurement of sulfur dioxide emissions using an ultraviolet light sensitive video system, JAPCA J. Air Waste Ma., 36, 42-47, 1986. 
Mori, T. and Burton, M.: The $\mathrm{SO}_{2}$ camera: A simple, fast and cheap method for ground-based imaging of $\mathrm{SO}_{2}$ in volcanic plumes, Geophys. Res. Lett., 33, L24804, doi:10.1029/2006GL027916, 2006.

Mori, T., Mori, T., Kazahaya, K., Ohwada, M., Hirabayashi, J., and Yoshikawa, S.: Effect of UV scattering on $\mathrm{SO}_{2}$ emission rate measurements, Geophys. Res. Lett., 33, L17315, doi:10.1029/2006GL027916, 2006.

Oppenheimer, C., Francis, P., Burton, M., Maciejewski, A., and Boardman, L.: Remote measurement of volcanic gases by Fourier transform infrared spectroscopy, Appl. Phys. B, 67, 505$515,1998$.

Platt, U. and Stutz, J.: Differential absorption spectroscopy, Springer, 2008.

Rufus, J., Stark, G., Smith, P. L., Pickering, J., and Thorne, A.: High-resolution photoabsorption cross section measurements of $\mathrm{SO}_{2}, 2: 220$ to $325 \mathrm{~nm}$ at $295 \mathrm{~K}$, J. Geophys. Res.-Planet, 108, 5011, doi:10.1029/2002JE001931, 2003.
Schnaiter, M., Horvath, H., Möhler, O., Naumann, K.-H., Saathoff, H., and Schöck, O.: UV-VIS-NIR spectral optical properties of soot and soot-containing aerosols, J. Aerosol Sci., 34, 14211444, 2003.

Tamburello, G., Kantzas, E., McGonigle, A., Aiuppa, A., and Giudice, G.: UV camera measurements of fumarole field degassing (La Fossa crater, Vulcano Island), J. Volcanol. Geoth. Res., 199, 47-52, 2011a.

Tamburello, G., Kantzas, E. P., McGonigle, A. J., and Aiuppa, A.: Vulcamera: a program for measuring volcanic $\mathrm{SO}_{2}$ using UV cameras, Ann. Geophys.-Italy, 54, 2, doi:10.4401/ag-5181, 2011 b.

Vandaele, A., Simon, P. C., Guilmot, J. M., Carleer, M., and Colin, $\mathrm{R}$.: $\mathrm{SO}_{2}$ absorption cross section measurement in the UV using a Fourier transform spectrometer, J. Geophys. Res.-Atmos., 99, 25599-25605, 1994. 